\title{
EvoDevo
}

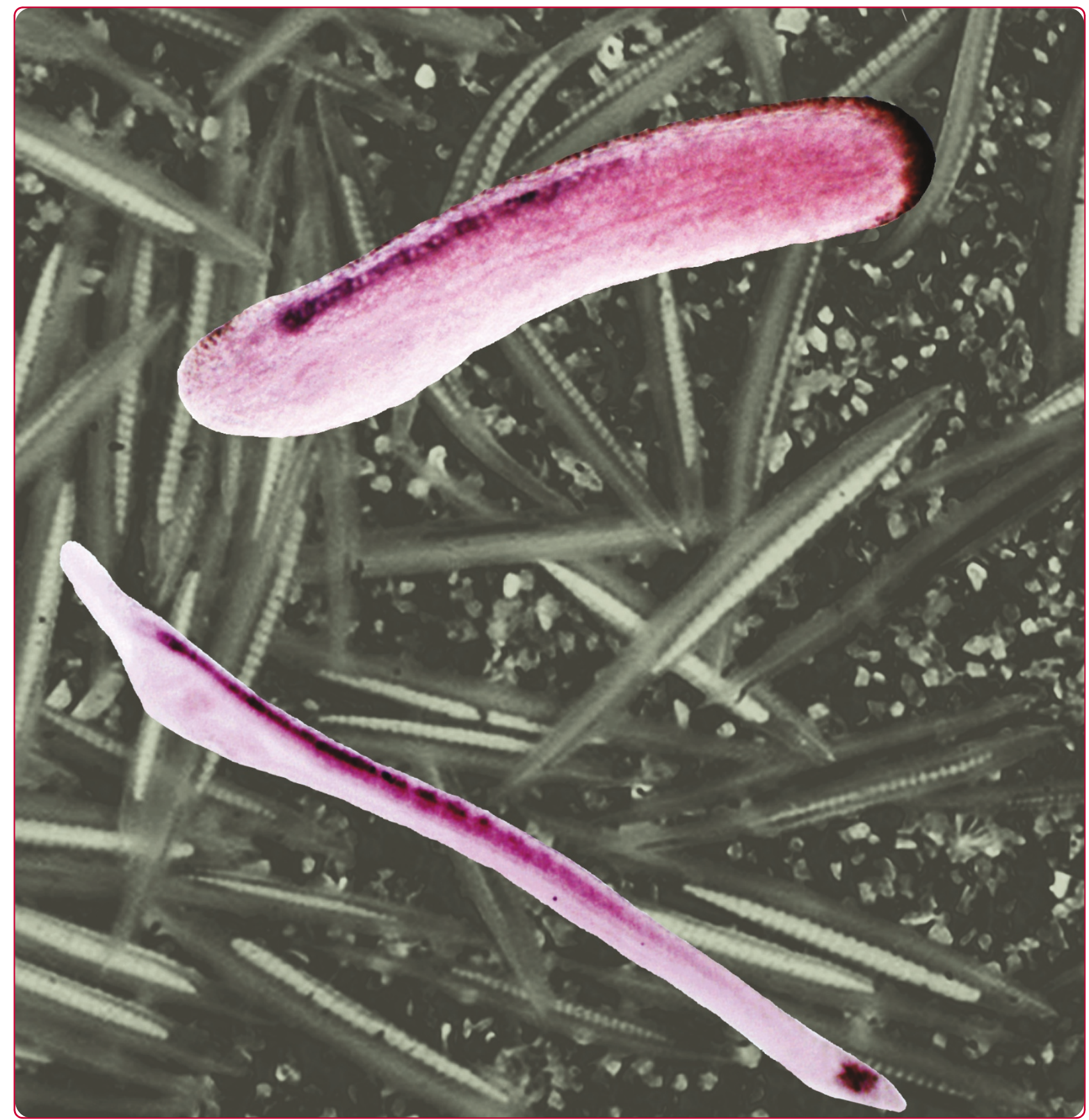

\section{A study of neural-related microRNAs in the developing amphioxus}

Candiani et al. 


\title{
A study of neural-related microRNAs in the developing amphioxus
}

\author{
Simona Candiani ${ }^{*}$, Luca Moronti ${ }^{1}$, Davide De Pietri Tonelli ${ }^{2}$, Greta Garbarino ${ }^{1}$ and Mario Pestarino ${ }^{1}$
}

\begin{abstract}
Background: MicroRNAs are small noncoding RNAs regulating expression of protein coding genes at posttranscriptional level and controlling several biological processes. At present microRNAs have been identified in various metazoans and seem also to be involved in brain development, neuronal differentiation and subtypes specification. An approach to better understand the role of microRNAs in animal gene expression is to determine temporal and tissue-specific expression patterns of microRNAs in different model organisms. Therefore, we have investigated the expression of six neural related microRNAs in amphioxus, an organism having an important phylogenetic position in terms of understanding the origin and evolution of chordates.

Results: In amphioxus, all the microRNAs we examined are expressed in specific regions of the CNS, and some of them are correlated with specific cell types. In addition, miR-7, miR-137 and miR-184 are also expressed in endodermal and mesodermal tissues. Several potential targets expressed in the nervous system of amphioxus have been identified by computational prediction and some of them are coexpressed with one or more miRNAs.

Conclusion: We identified six miRNAs that are expressed in the nervous system of amphioxus in a variety of patterns. miR-124 is found in both differentiating and mature neurons, miR-9 in differentiated neurons, miR-7, miR137 and miR-184 in restricted CNS regions, and miR-183 in cells of sensory organs. Therefore, such amphioxus miRNAs may play important roles in regional patterning and/or specification of neuronal cell types.
\end{abstract}

\section{Background}

MicroRNAs (miRNAs) are a large class of non-coding RNAs involved in post-transcriptional regulation. They were first discovered in nematodes and subsequently found to be widely distributed in plants and animals [1-4]. miRNAs are 18 to 24 nucleotides long and regulate translation by binding to the respective mRNA transcripts, either inducing mRNA degradation or directly inhibiting translation. In animals, miRNAs bind to specific bases in the 3' untranslated regions (UTR) of mRNA targets [5]. Each miRNA can regulate translation of several genes and modulate many biological processes such as developmental timing, cell proliferation, cell death, Hox gene expression and early embryogenesis [6]. miRNAs play also important roles in stem cell biology, furthermore altered miRNA functions have been implicated in a number of human disorders and cancers [7].

\footnotetext{
* Correspondence: candiani@unige.it

${ }^{1}$ University of Genoa, Department of Biology, viale Benedetto XV 5, 16132 Genoa, Italy

Full list of author information is available at the end of the article
}

In particular, miRNAs are known to regulate translation of a number of genes involved in development of the central nervous system (CNS) [8-10].

miRNAs are to a large extent evolutionarily conserved. The basal chordate amphioxus has 115 miRNA families, 55 of which are homologous to those of vertebrates [11-13]. Amphioxus has a prototypical chordate genome with a high degree of synteny with vertebrate genomes $[14,15]$, and a body plan that is also similar to that of vertebrates. Although the amphioxus CNS has comparatively few neurons-an estimated 20,000 in the adult [16] and lacks a neural crest [17], the basic organization of the amphioxus CNS is comparable to that in vertebrates. Comparisons of gene expression and mapping of neurons and their connections have indicated that the amphioxus CNS consists of a diencephalic forebrain (the telencephalon is lacking), a small midbrain, a hindbrain and spinal cord $[18,19]$. The forebrain and small midbrain are together termed the cerebral vesicle. Thus, the most anterior photoreceptor (the frontal eye) is thought to be homologous to the vertebrate paired eyes, 
the lamellar body in the dorsal part of the amphioxus diencephalon is considered to be homologous to the vertebrate pineal complex, and secretory cells in the floor of the diencephalon are thought equivalent to the vertebrate infundibulum which produces Reissner's fiber [19]. In addition to the frontal eye, there are many other photoreceptors in the amphioxus CNS. Those developing in the hindbrain and spinal cord, called the organs of Hesse, are rhabdomeric or microvillar photoreceptors, while those in the forebrain, except for the Joseph cells, are ciliary photoreceptors. The organs of Hesse and the frontal eye consist of pigment cells containing melanin together with one or more photoreceptive neurons. However, the lamellar body, a ciliary photoreceptor, and the Joseph cells, which are rhabdomeric photoreceptors located in the posterior part of the cerebral vesicle, are not associated with pigment cells. The first photoreceptor to develop is an organ of Hesse in the middle of the hindbrain. The second is the frontal eye [20]. About the same time that the first organ of Hesse forms, at the early to mid-neurula, two rows of motor neurons also differentiate. Not surprisingly, the larvae are positively phototropic from the mid-neurula stage and begin muscular movements at the late neurula stage.

Gene expression is quite similar in the CNS of both amphioxus and vertebrates. Not only is the expression of genes involved in rostro-caudal patterning such as Otx, Hox and Gbx highly conserved [21-23], but also the expression of genes involved in the neuronal specification. For example, the ERR, islet, Shox, Krox, $M n x$ genes are expressed in developing motor neurons in both amphioxus and vertebrates [24-27]. However, it is not known whether expression of miRNAs is similar in the amphioxus and vertebrate CNS. In vertebrates, several miRNAs are expressed in specific brain regions or specific types of neurons suggesting their involvement both in development and function of the nervous system [8]. For example, in Xenopus, miR-124 is expressed in the optic vesicle and forebrain, where it negatively regulates NeuroD1 [9]. In the mouse brain, miR-124 seems to be largely restricted to differentiating and mature neurons [28], while miR-124 is expressed in neural progenitors $[10,28]$. Its expression appears to be controlled by a neuron restricted transcriptional repressor (REST/NRSF), which inhibits miR-124 expression in both nonneuronal cells and neural progenitors [29]. A second miRNA, miR-9, is also specifically expressed in proliferating neural precursors in both zebrafish embryos [30,31], and in mouse embryos and adults [28,32], while miR-7 and miR-184 are expressed in several types of brain tumors, suggesting a function in cell proliferation [33-36]. In addition, miR-137 has been implicated in proliferation of neural stem cells $[37,38]$, while mir183 is expressed in hair cells in the vertebrate ear $[39,40]$.

For amphioxus, there is only a single study of miRNA expression, which showed that two miRNAs (miR-133 and miR-1) are expressed in the developing muscular somites of amphioxus [13]. Therefore, to gain insights into the evolution and function of miRNAs during amphioxus neural development, we determined expression of six miRNAs (miR-124, miR-9, miR-7, miR-183, miR-184 and miR-137) in two species of amphioxus, Branchiostoma floridae and B. lanceolatum. All six miRNAs are known to be expressed exclusively or preferentially in the nervous systems of vertebrates and/or other species. Our results show that all six miRNAs are expressed in specific regions of the CNS of amphioxus, many of which can be correlated with cell types identified by microanatomical studies [20,41-43]. In addition miR-7, miR-137 and miR-184 are also expressed in endodermal and mesodermal tissues. Together with analysis of potential miRNA targets, these results give insights into the regulation of neurogenesis in amphioxus.

\section{Results}

We found that all six miRNAs are expressed in the amphioxus CNS, although miR-7, miR-184 and miR-137 are also present in a strikingly broad spectrum of developing tissues derived from mesoderm and endoderm, while miR-183 is also expressed in some ectodermal sensory cells of the peripheral nervous system (PNS).

\section{miR-124 expression during amphioxus development}

In both B. floridae and B. lanceolatum, the earliest miR-124 expression appears in $14 \mathrm{~h}$ mid-neurulae in a periodic pattern of cells on each side of the midline adjacent to the first five somites (Figure 1A, B). As development proceeds, expression is visible in two longitudinal rows of labeled nerve cells beginning at the posterior cerebral vesicle (cv) and extending to the hindbrain (Figure 1C, D). Plastic sections of the same embryos show that such cells are preferentially lateral and ventrolateral (Figure 1F-I) except for a few neurons in the floor plate and adjacent to the pigment cell of the first photoreceptor to form (Figures $1 \mathrm{H}$ ). In later larvae (three to four gill slits), expression of miRNA expands anteriorly into the cerebral vesicle, but does not reach the anteriormost portion at any stage examined (Figures $1 \mathrm{~J}-\mathrm{M}$ and 2A, B). In particular, two areas of the cerebral vesicle express miR-124: one in the middle and the second in the posterior half of the cerebral vesicle (Figure 2B). Cross sections at different levels of the nervous system showed that most labeled cells are in the ventro-lateral neural tube (Figure 2D, E and 2H) whereas very few labeled cells were located in the dorsal wall (Figure 2F). Expression in the 


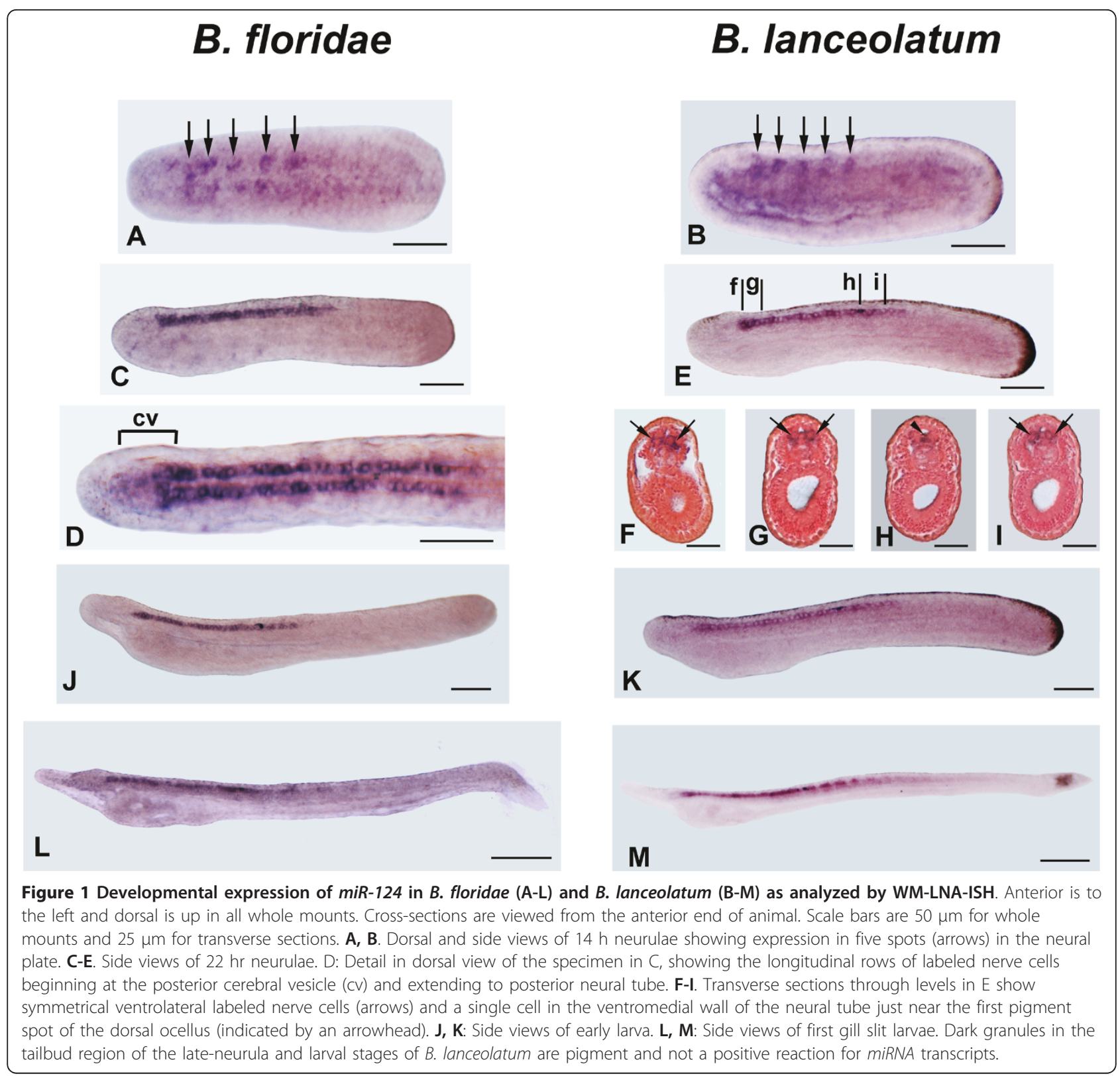

two rows of ventro-lateral cells also expands posteriorly into the spinal cord during larval development (Figure $2 \mathrm{~A}-\mathrm{H}$ ). This is in agreement with the pattern of neurogenin, which initially labels neurons anteriorly in the CNS with the pattern moving posteriorly as development proceeds.

\section{miR-9 expression in late larval stage of amphioxus $B$.}

\section{floridae}

miR-9 expression was never detected in embryos or very early larvae of both $B$. floridae and $B$. lanceolatum, in contrast to the situation in vertebrates [30,31]. Instead, miR-9 expression appears only later in larvae (three to four gill slits) (Figure 2I). Here, we show miR-9 expression exclusively in the B. floridae. miR-9 is expressed in scattered cells throughout the neural tube except at the most anterior part of the cerebral vesicle where the frontal eye has just formed (Figure 2J). Just posterior to the frontal eye, we observed miR-9 transcripts in a very few dorsal cells of the cerebral vesicle (Figure 2J, L). The miR-9 labelled cells cannot be the same as those expressing miR-124, because the former are organized as segmental blocks of cells (Figure 2K, $\mathrm{O})$, while the latter, although segmentally arranged at an early stage, are no longer segmentally arranged in the larva (Figure 2B, C, G). Moreover, transverse sections 


\section{miR-124}
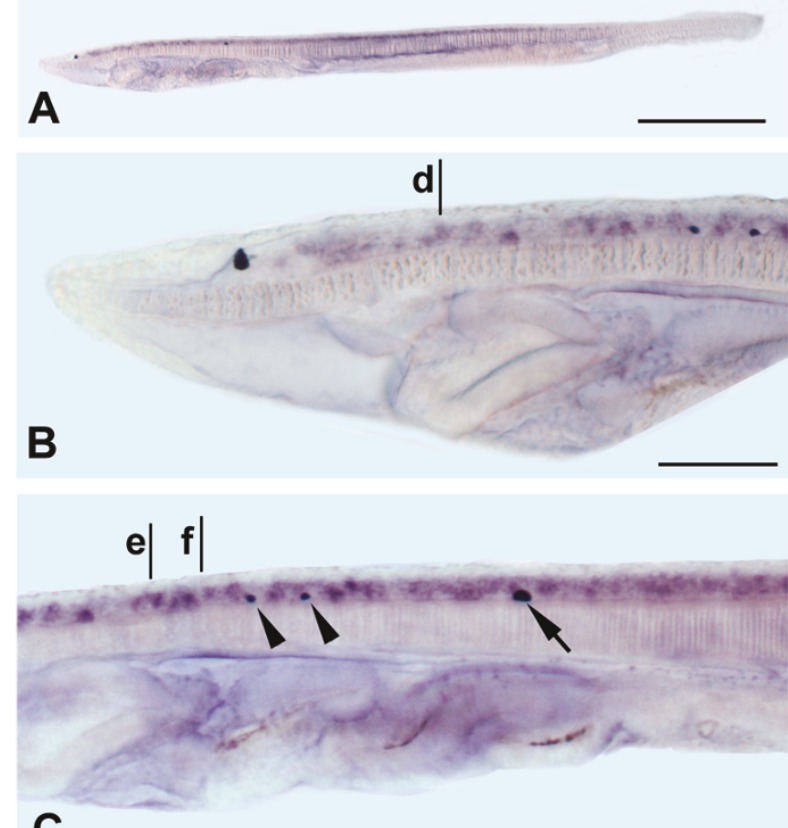

C
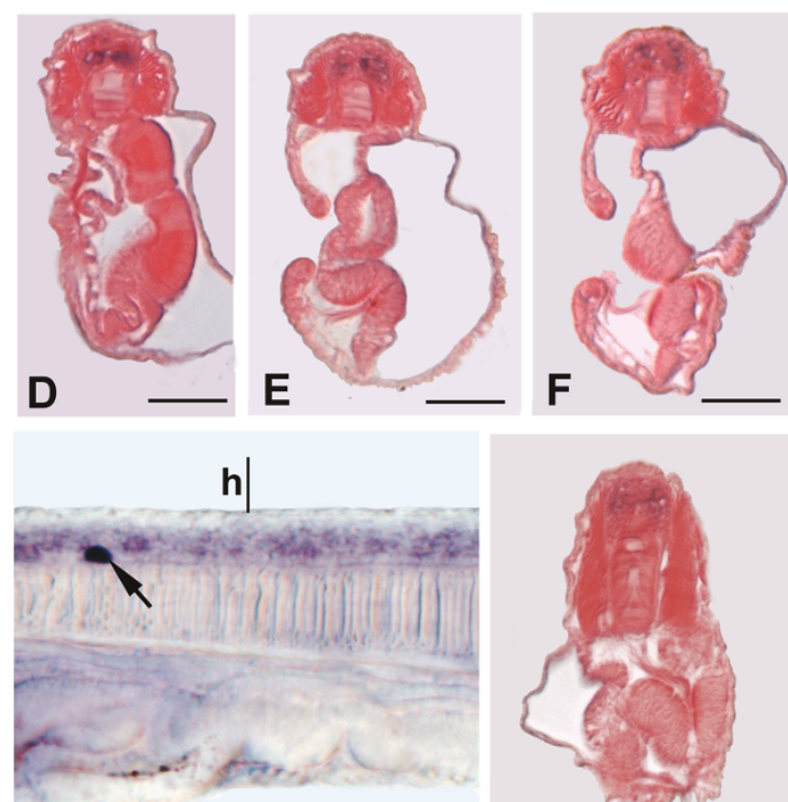

G

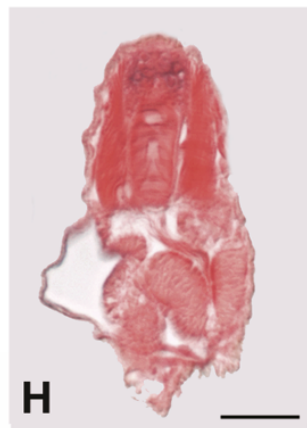

miR-9
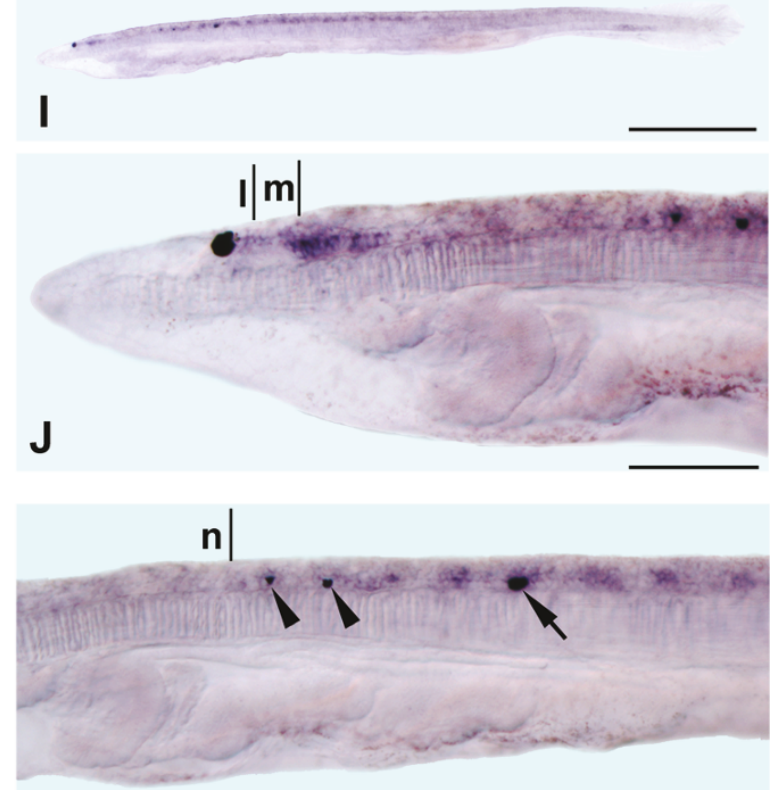

K
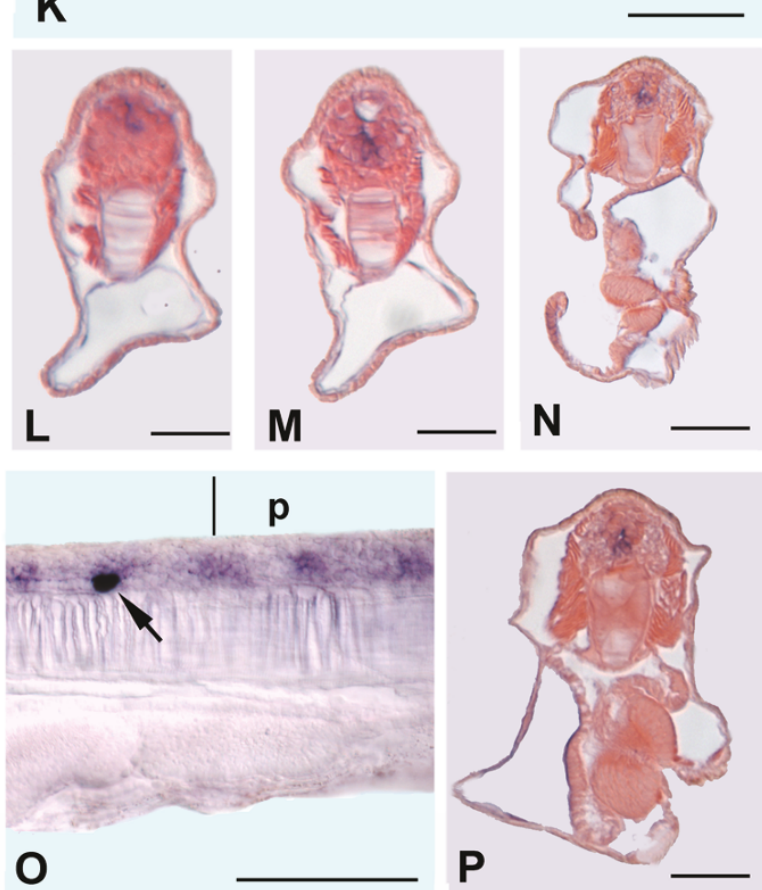

Figure 2 Comparison between miR-124 and miR-9 expression at late larval stage of $B$. floridae. Anterior to the left. Cross section scale bars are $25 \mu \mathrm{m}$. A, I: Side views of larvae with three to four gill slits. Scale bars: $250 \mu \mathrm{m}$. B, J. Anterior enlargement of specimens in A and I, respectively. Scale bars: $50 \mu \mathrm{m}$. C, K. Enlarged view of the neural tube of specimen in A and I at level of three dorsal ocelli (the first dorsal ocellus appearing during the development and located near the somite 5 is shown by arrows, the most anterior ones are indicated by arrowheads. Each differing from the first dorsal ocellus in being bicellular associations between a single neuron and a single pigment cell). Scale bars: $50 \mu \mathrm{m}$. D: Cross section through level d in B. E, F: Cross sections through levels e and $\mathrm{f}$ in $\mathbf{C}$. L, M: Cross section through levels I and $\mathrm{m}$ in J. $\mathbf{N}$ : Cross section through level $n$ in $\mathbf{K}$. G, O: Detail of specimens in A and I at levels of the first dorsal ocellus (arrows). Scale bars: $50 \mu m$. $\mathbf{H}, \mathbf{P}$ : Cross sections through levels $h$ and $p$ in $G$ and $O$, respectively. 
clearly demonstrate that miR-9 expressing cells are mainly in the ventral midline of the neural tube (Figure $2 \mathrm{M}, \mathrm{N}, \mathrm{P}$ ), while those of miR-124 are more lateral (Figure 2D-F, H).

\section{miR-7 expression in amphioxus}

Unlike miR-124 and miR-9, expression of miR-7 is not limited to the CNS. The first miR-7 expression appears at the late neurula stage (20 to 22 hours after fertilization) as a weak signal in the ventral portion of the cerebral vesicle (Figure 3A, J). At the late neural stage, miR7 transcripts were also found in the most anterior end of the pharyngeal endoderm (Figure 3A) from which Hatschek's left anterior diverticulum, also known as the preoral organ or Hatschek's pit (a putative homolog to the vertebrate adenohypophysis), will originate. In the early larva, miR-7 is detectable in almost the entire ventral portion of the cerebral vesicle including the photoreceptors of the frontal eye (Figure 3B-E, 3I, J). Finally, a restricted expression was also observed in Hatchek's pit (Figure 3C, F, G, J).

\section{miR-183 expression in amphioxus larvae}

miR-183 expression is largely restricted to the CNS, but it is also expressed in some likely ectodermal sensory cells in the anterior end of the larva. The expression of miR-183 starts from the larval stage and it does not differ substantially between B. lanceolatum and B. floridae at $72 \mathrm{hr}$ of development (Figure 4). Strong expression was detected in two groups of epidermal cells in the rostrum: the first is confined to the most anterior tip (Figure 4A, B, D, G, H), and the second is localized in the ectoderm anterior to the cerebral vesicle and adjacent to the notochord (Figure 4C, E, G, $\mathrm{H}$ ), approximately where an anterior sense organ (the corpuscles of de Quatrefages) will later develop [44]. miR-183 was also found in some dorsolateral cells on either side of the posterior cerebral vesicle (Figure 4A, B, F-H). At least some of these cells are located approximately where the lamellar organ is developing. Finally, a few scattered cells expressing miR-183 were also found in the CNS posterior to the cerebral vesicle (Figure 4A, G, H).

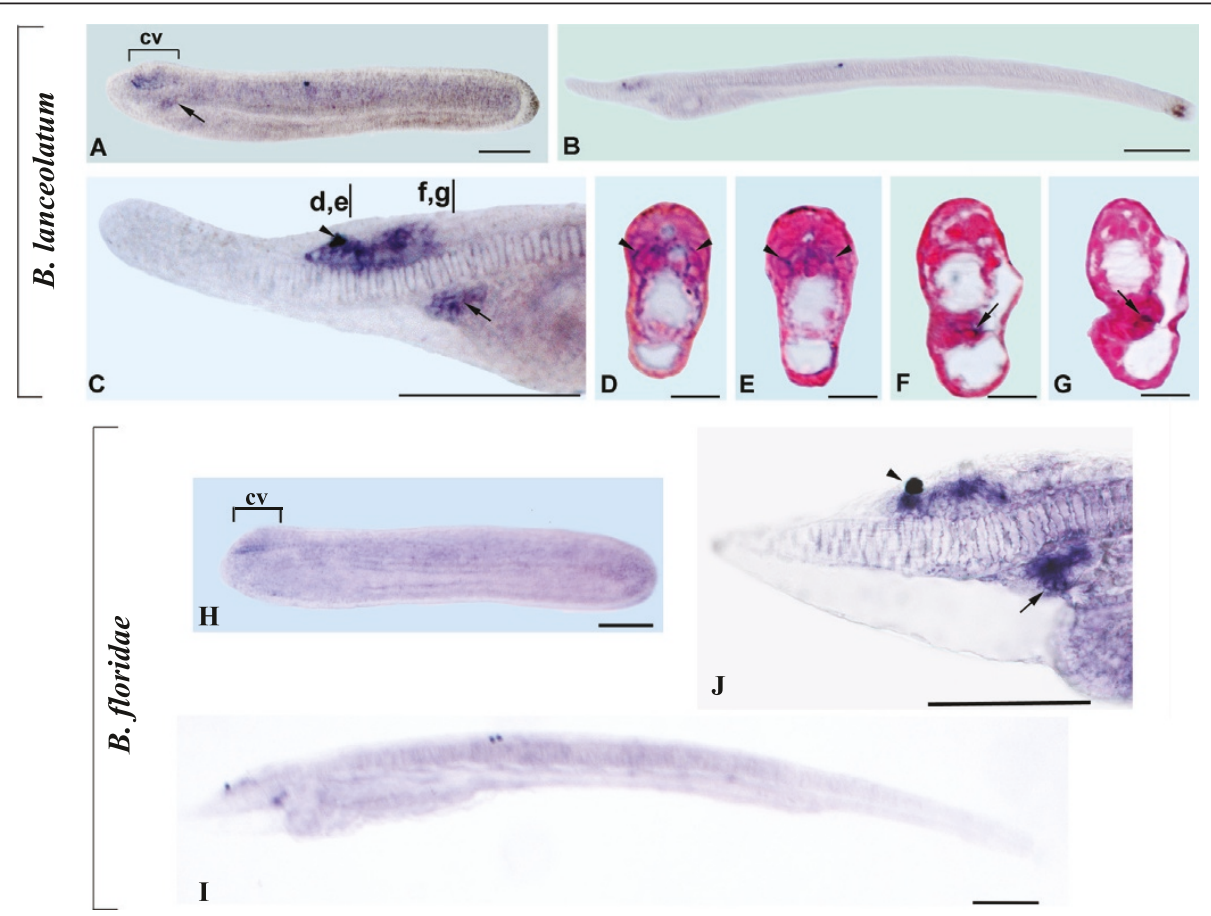

Figure 3 miR-7 expression in B. Ianceolatum and B. floridae. Anterior to the left and dorsal up in all whole mounts. Cross-sections are viewed from the anterior end of animal. Scale bars are $50 \mu \mathrm{m}$ for whole mounts and $25 \mu \mathrm{m}$ for cross sections. A: Side view of 22-h neurula. Expression is restricted to the cerebral vesicle (cv) and anterior pharyngeal endoderm (arrow). B: Side view of a first gill slit larva. C: Higher magnification of the anterior end of larva in B. Expression is observed in cerebral vesicle and preoral pit (arrow). D, E: Cross sections through levels $d$ and e in $C$ show several ventrolateral labeled cells of the anterior cerebral vesicle (arrowheads). F, G: Cross sections through levels $f$ and $\mathrm{g}$ in C show miR-7 expression in cells of preoral pit (arrows). H: Side view of 20-h neurula showing expression in the cerebral vesicle. I: Side view of a three gill slit larva. J: Anterior enlargement of the anterior end of the specimen in I. miR-7 is expressed in cells of the frontal eye complex and in further regions of cerebral vesicle (cv). A strong signal was also found in the preoral pit (arrow). Arrowhead in C and J points to pigment spot associated with frontal eye. 


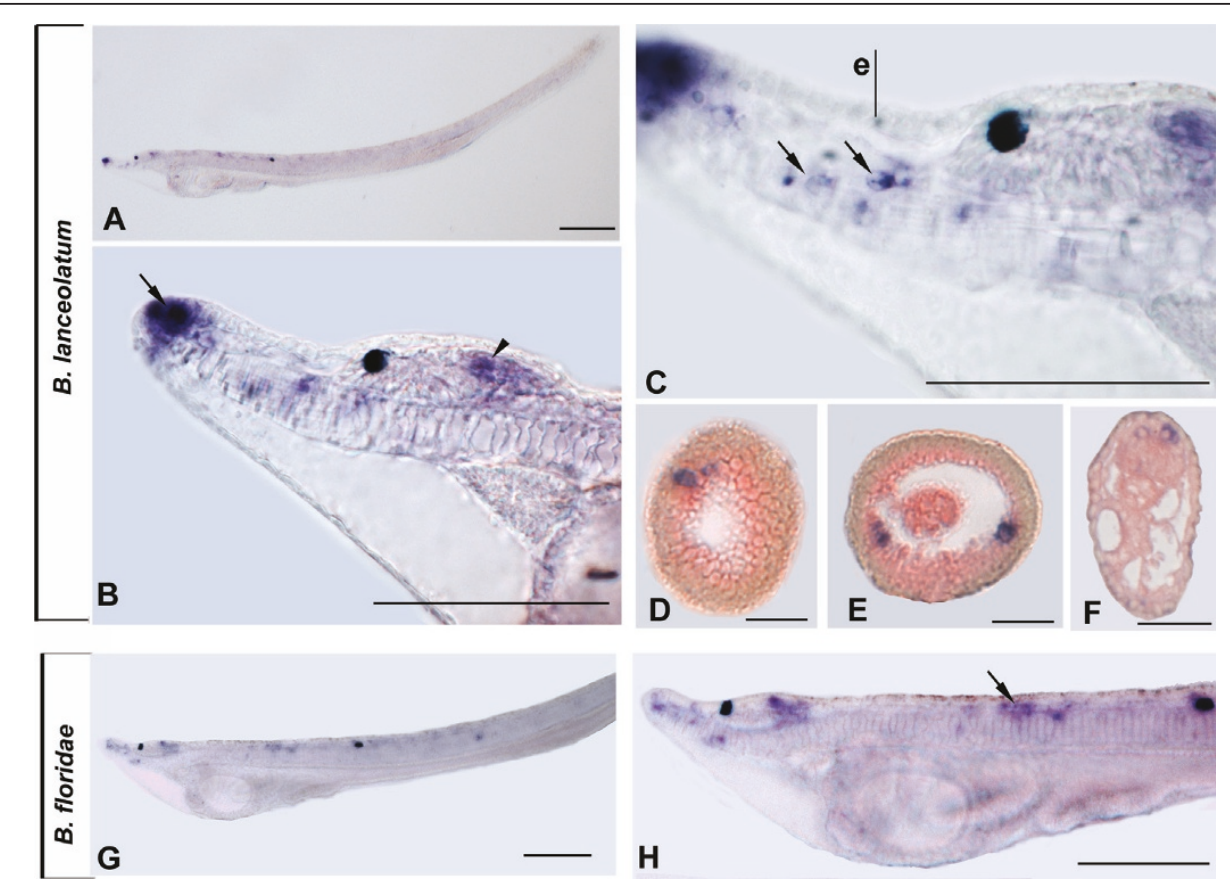

Figure 4 miR-183 expression in B. lanceolatum and B. floridae. Anterior to the left and dorsal up in all whole mounts. Cross-sections are viewed from the anterior end of the animal. Scale bars are $50 \mu \mathrm{m}$ for whole mounts and $25 \mu \mathrm{m}$ for cross sections. A: Side view of a $72-\mathrm{h}$ larva. B: Detail of the head region of larva in A showing expression in epidermal cells located in the most anterior tip of rostrum (arrow) and in dorsal wall of the posterior cerebral vesicle (arrowhead). C: Higher magnification of specimen in A with in focus labeled epidermal cells on the sides of the rostrum (arrows). D, F: Cross sections through the levels indicated by an arrow (D) and an arrowhead (F) in B, respectively. E: Cross section through level e in C. G: Side view of B. floridae larva. H: Enlargement of the specimen in G showing expression in epidermal cells of rostrum, cells of the dorsal posterior region of cerebral vesicle and in scattered cells of the neural tube (arrow).

\section{miR-184 expression in amphioxus}

mir-184 is expressed very early during development in both $B$. floridae and B. lanceolatum (Figure 5). It is ubiquitously expressed in two-cell embryos (Figure 5A, $\mathrm{K})$. By the 16-cell stage, expression is limited to the vegetal blastomeres (Figure $5 \mathrm{~B}, \mathrm{~L}$ ), although in the early blastula, it is also expressed, albeit at a lower level, in the animal blastomeres (Figure $5 \mathrm{C}, \mathrm{M}$ ). At the gastrula stage, mir-184 is expressed throughout the presumptive neuroectoderm and at a higher level throughout the mesendoderm (Figure 5D, N). At the early (Figure 5O) and mid-neurula stages (Figure 5E, $\mathrm{P})$, we detected expression in the entire neural tube, somites and posterior endoderm. This pattern is also maintained at the late neurula stage (Figure $5 \mathrm{~F}-\mathrm{H}$ ), where miR-184 transcripts are evident in the cerebral vesicle (Figure $5 \mathrm{G}$ ), somites (Figure $5 \mathrm{H}$ ) and in a group of ventral endodermal cells from which will arise the first gill slit (Figure 5F). Finally, at the larval stage, transcripts of miR-184 are detectable in the anterior and intermediate regions of the cerebral vesicle, in the preoral pit, and in two pharyngeal organs (endostyle and club shaped gland) (Figure 5J, R) as well as in cells surrounding the first (Figure 5I) and second gill slits (Figure 5Q).
miR-137 expression in amphioxus

miR-137 transcripts were first discernable during the neurula stage of B. lanceolatum (Figure 6) and B. floridae (data not shown). In the mid-neurula, expression was found exclusively in the most anterior end of the neural tube, the presumptive cerebral vesicle (Figure 6A). In the early larva (24 to 30 hours after fertilization), the signal was confined to a very few cells in the posterior cerebral vesicle (Figures 6B and 7A, B). From this stage onward, this signal gradually becomes more intense (Figures 6C, D and $7 \mathrm{C}$ ). Transverse sections indicated that at least some of the labeled cells probably are in the presumptive infundibular organ (Figure 6E, F). However, miR-137 is likely also found just posterior to the infundibular organ in the tegmental neuropile. Subsequently, expression of miR-137 extended to an additional group of cells more anteriorly in the cerebral vesicle (Figures 6G, H and 7D, E) and also to cells arranged in a periodic pattern more posteriorly in the neural tube (Figures 6G, K-N and 7D-F). Non-neural expression was also found around the mouth and in the developing gill slits (Figures 6G and 7D, E)

\section{Amphioxus predicted miRNA targets}

At present in silico prediction is generally the first approach that is used to identify potential miRNA 


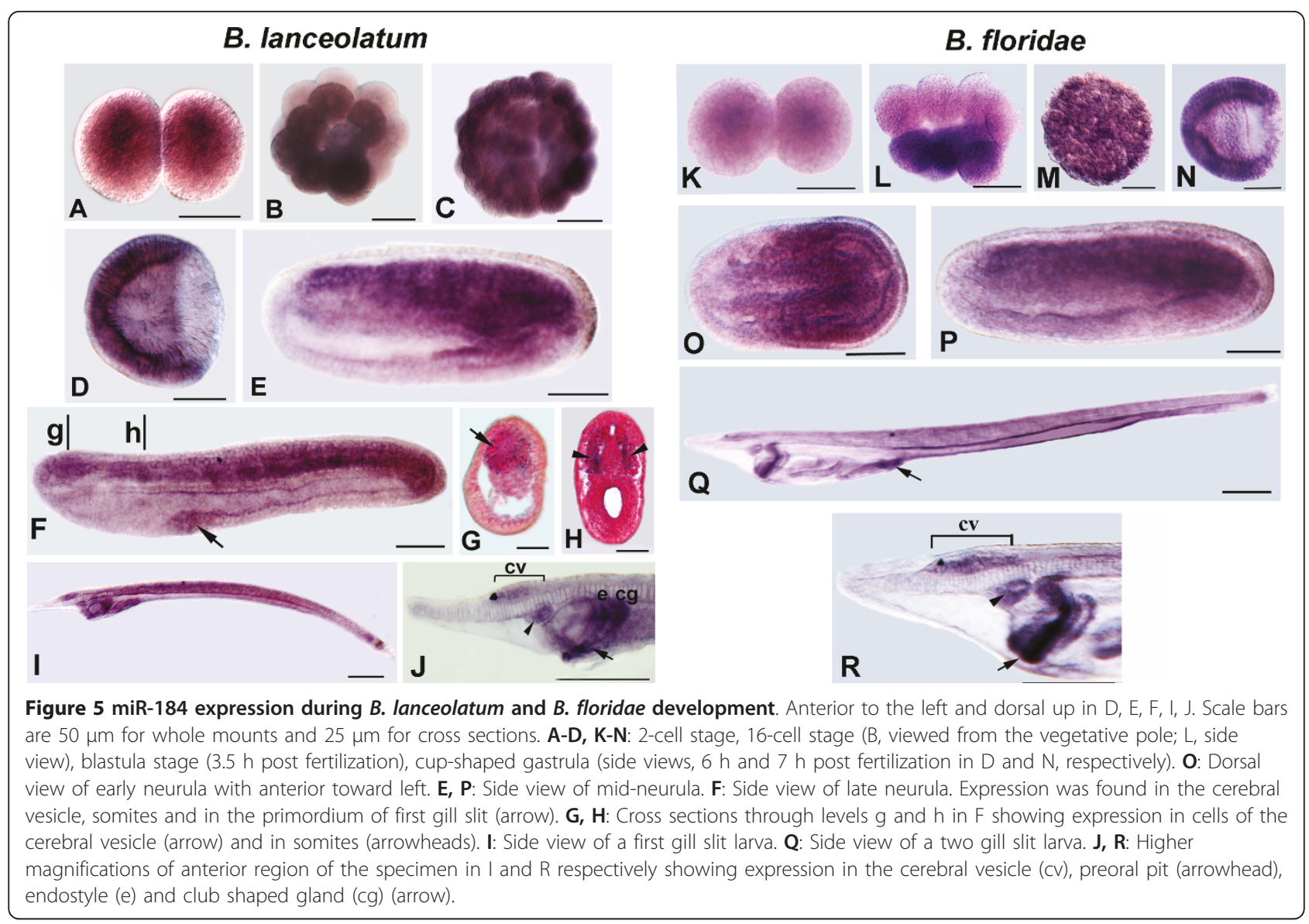

targets. Table 1 and Additional file 1 (Tables S1 and S2) show that miR-124, miR-7, miR-183, miR-184 and miR137 probably regulate different target genes, some of which could be regulated by many miRNAs. Comparison of the expression patterns of these miRNAs with those of their putative target mRNAs revealed both overlapping and non overlapping expression. Animal microRNA target prediction is particularly challenging because of the complexity of miRNA target recognition. At present, comprehensive rules controlling miRNA target recognition and binding have not been discovered, and false positive and false negative results are a problem. In animals, miRNA:mRNA duplexes often contain several mismatches, gaps and G:U base pairs in many positions, which limit the length of contiguous sequences of perfect nucleotide matching.

Often miRNAs inhibit translation of their direct targets, and, therefore, the miRNA and its target are coexpressed. However, miRNAs may also regulate the levels of expression of their target mRNAs. This mode of gene regulation is generally linked to a non overlapping expression between miRNAs and their targets [45-47]. However, there are also examples of partially or completely overlapping expression of targets and
miRNAs [48]. Alternatively, the target can be expressed in cells that express the miRNA but at higher levels in those cells that do not express the miRNA $[49,50]$. Here, we used four different programs (miRanda, FindTar, RNAhybrid and PITA) to predict putative amphioxus miRNA targets. We argued that if at least three programs predict the same target sites, the likelihood of false positives is reduced [51]. Unfortunately, several common programs used for vertebrates, Drosophila and worms (ex. TargetScan and PicTar) are not available for "non standard" animal species such as amphioxus. Thus, we have erred on the side of caution and may have missed a number of targets. Indeed, almost one third of the predicted targets were not common to the data generated by three of the four methods.

Therefore, we searched 3'UTR sequences of 68 genes of $B$. floridae for potential binding sites of the six miRNAs (Additional file 1 Table S2). In particular, we selected some genes that are expressed in the nervous system during amphioxus development (Additional file 1 Table S2). For some of them expression in B. lanceolatum is also known [52] (Table 1). Of 68 genes expressed in the amphioxus nervous system, we found 17 


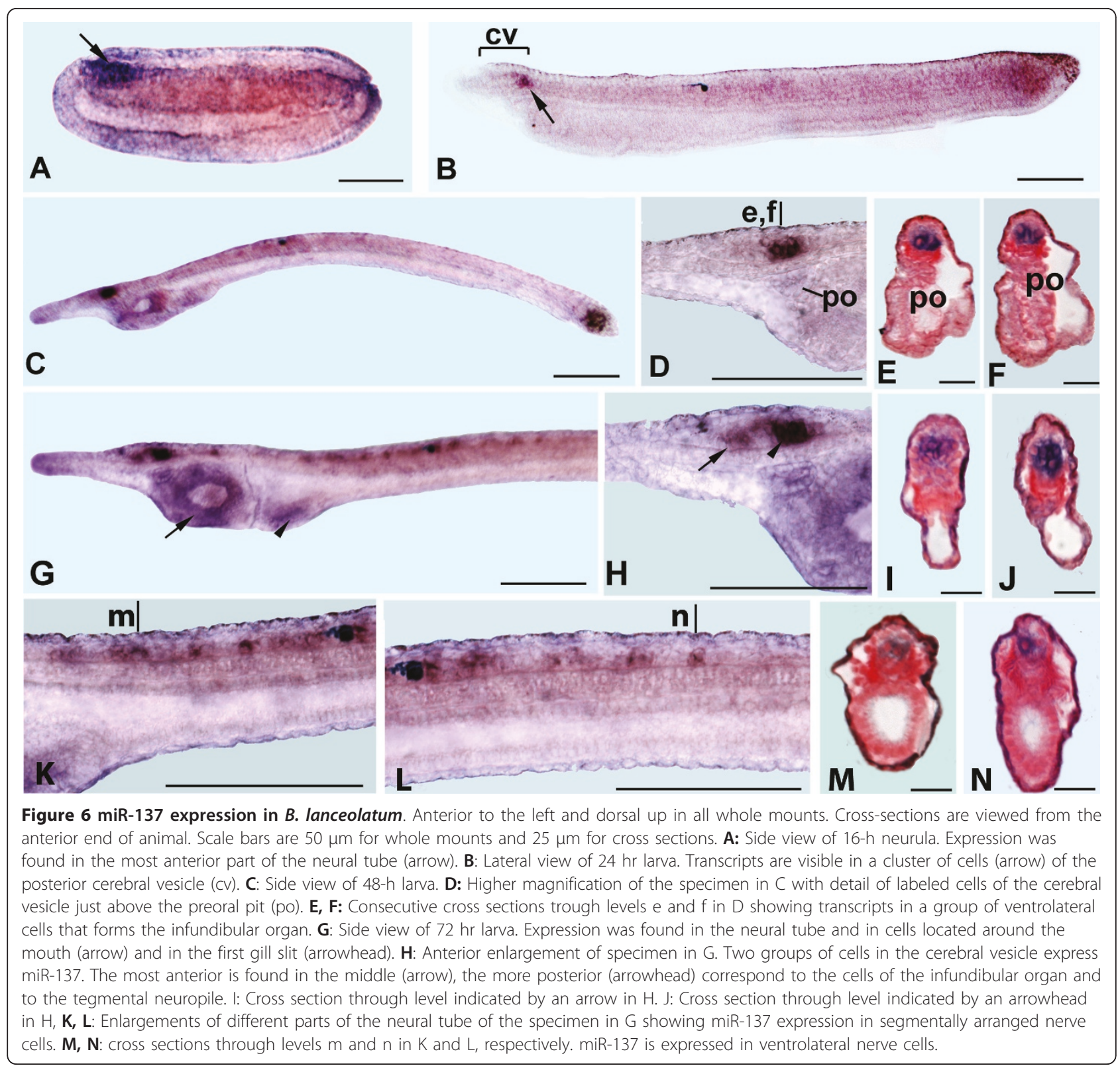

transcripts with one or more sites for the 5 miRNAs (Table 1 and Additional file 1 Table S1). miR-9 does not show hits for the selected transcripts. Only eight miRNAs were predicted by at least 4 methods to bind at the same site. Our analysis shows that among 17 putative targets, expressed in the CNS of amphioxus, 13 are coexpressed with the one or more of the 5 miRNAs and 6 are not coexpressed (Table 1 and Additional File 1 Table S1). Therefore, we hypothesize that amphioxus miRNAs regulate targets both by controlling translation and by mRNA degradation.

Comparison of the expression patterns of the six miRNAs and their potential targets shows that only miR184 , which is very broadly expressed, is co-expressed with all the potential targets we identified (Table 1 and Additional file 1 Table S1). For example, in the CNS, miR-184 is co-expressed in the cerebral vesicle with calmodulin, FoxG (BF1), TH, TR2/4, Otx. In contrast, none of the selected transcripts contains target sites for miR-9. However, since there are relatively few data concerning gene expression at the late larval stage of amphioxus when miR-9 starts to be expressed, it is difficult to compare its expression with that of other potential targets.

The other 4 miRNAs are all co-expressed with one or more of their potential targets in the CNS. For example, among the several predicted targets of miR-124 expressed in the nervous system (Table 1 and Additional 


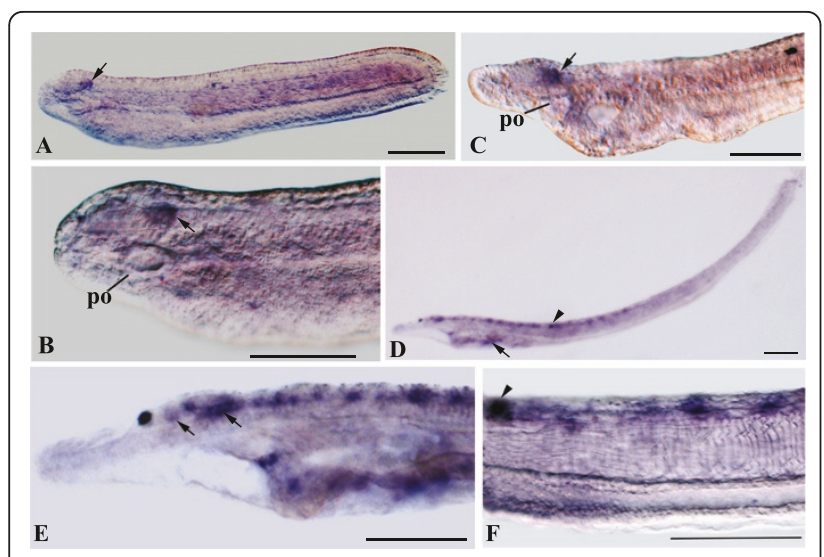

Figure 7 miR-137 expression in B. floridae. A: Side view of 24-h larva. B: Anterior enlargement of the specimen in A showing expression in a discrete region of the posterior cerebral vesicle just above the preoral pit (po). c: Higher magnification of the anterior end of a 30-h larva. D: Side view of a three gill slit larva with expression in the neural tube and gill slits (arrow). E: Anterior of larva in D showing expression in different cells of cerebral vesicle (arrows) and in segmentally arranged cells of the neural tube just posterior. F: Enlargement of the posterior neural tube just posterior to the pigment of the first dorsal ocellus (arrowhead) with miR-137 transcripts in cells segmentally arranged in the neural tube.

file 1 Table S1) only Chordin is co-expressed and only at the late neurula stage. At the larval stage, expression of the two no longer overlaps as chordin expression becomes restricted to the cerebral vesicle, where miR124 is never expressed. Expression of FoxG (BF1), Hairy
A, Wnt8 and Calmodulin never overlaps with that of miR-124. Transcripts of FoxG (BF1), Wnt8 and Calmodulin in the CNS are limited to the cerebral vesicle, while those of Hairy A in the CNS are posterior to that of miR-124, and by the larval stage become confined to endodermally-derived structures (Table 1).

The only putative target of miR-7 is NK2.2. In the CNS, expression of miR-7 and $N K 2.2$ appears to overlap in the posterior $2 / 3$ of the cerebral vesicle at the late neurula and larval stages. However, NK2.2 is also expressed in gut cells, while miR-7 is expressed in the preoral pit.

Among the predicted amphioxus targets of miR-183 we found two genes showing an overlapping expression: Calmodulin and Netrin (Table 1). For example, at larval stage Netrin is found in the lamellar body as mir-183. On the contrary, $G b x$ and $a x 2 / 5 / 8$ are putative targets of miR-183 known to be expressed at larval stage in the hindbrain region where miR-183 is not present (Table 1).

Putative targets of amphioxus miR-137 are Six-4/5, TR2/4/and Gbx (Table 1). Of these, the first two are coexpressed with miR-137. Six-4/5 and TR2/4 are overlapping with miR-137 in some regions of cerebral vesicle and in cells of the mouth and gill slits, whereas $G b x$ is a putative target not coexpressed with miR-137.

\section{Discussion}

Cephalochordates, commonly known as amphioxus or lancelets, are the most basal, living group of chordates.

Table 1 Coexpression of miRNAs and enriched brain putative targets

\begin{tabular}{|c|c|c|c|c|c|c|}
\hline $\begin{array}{c}\text { putative } \\
\text { miRNA targets }\end{array}$ & miR-124 & miR-7 & miR-183 & miR-137 & miR-184 & References \\
\hline Calmodulin & FT-RH-Mir & & FT-RH-Mir & & FT-Pita-RH-Mir & [109] \\
\hline Chordin & Pita-RH-Mir & & & & & {$[110,52]$} \\
\hline Coe & & & & & FT-Pita-RH-Mir & [111] \\
\hline Engrailed & & & & & FT-Pita-RH-Mir & [112] \\
\hline FoxG (BF1) & FT-Pita-RH-Mir & & & & FT-RH-Mir & [113] \\
\hline Gbx & & & FT-Pita-RH-Mir & FT-Pita-RH & & [23] \\
\hline Hairy A & FT-Pita-RH-Mir & & & & & {$[114]$} \\
\hline \multirow[t]{2}{*}{ Mnx (2 sites) } & & & & & FT-Pita-Mir & {$[27]$} \\
\hline & & & & & FT-Pita-RH-Mir & \\
\hline Netrin & & & FT-Pita-RH-Mir & & & [115] \\
\hline NK2.2 & & FT-RH-Mir & & & & {$[116]$} \\
\hline Otx & & & & & FT-Pita-RH & {$[21,52]$} \\
\hline Pax-2/5/8 & & & FT-Pita-RH & & & {$[117,52]$} \\
\hline Six-4/5 & & & & FT-RH-Mir & & [118] \\
\hline Snail & & & & & FT-RH-Mir & [119] \\
\hline $\mathrm{TH}$ & & & & & FT-RH-Mir & [120] \\
\hline TR2/4 & & & & FT-Pita-RH & FT-Pita-RH & [121] \\
\hline Wnt8 & Pita-RH-Mir & & & & & [122] \\
\hline
\end{tabular}

Expression of miRNA and enriched brain putative targets detected by at least three of the four bioinformatics algorithms (FindTar, Pita, RNAhybrid and miRanda). miRNA-target coexpression is written in bold. Abbreviations are the followings: FT, FindTar, RH, RNAhybrid, Mir, miRanda. 
At least 20 species of the genus Branchiostoma have been described but only three of them are mainly investigated: $B$. floridae in North America, B. lanceolatum in Europe, and B. belcheri in East Asia. Mitochondrial DNA sequences indicate that they probably diverged from 100 to 200 Mya [53,54]. These species are morphologically very much the same. For $B$. lanceolatum and $B$. floridae, the major differences in larvae are the long anterior end and the pigmented tail in the former. Given this high level of morphological conservation, it is not surprising that developmental gene expression is proving to be nearly identical in the two species [52]. Thus, it is not also surprising that miRNAs are conserved between $B$. floridae, B. belcheri and $B$. japonicum [11-13] (Figure 8) and that we found their expression patterns in at least $B$. floridae and $B$. lanceolatum also to be much the same. For the six mature miRNAs sequences investigated in the present study, there are a few differences in sequences including insertion/deletion of few nucleotides in the 3' ends of miR-9, miR-184, miR-183 and miR-137 (Figure 8), outside the 5 '-seed region (two to eight nucleotides), which is known to be involved in target recognition. In fact, there is also a high level of sequence identity among these miRNAs in vertebrates and Branchiostoma. During miRNA biogenesis, one strand of the RNA duplex is preferentially selected for entry into a silencing complex, whereas the other strand, known as the passenger strand or miRNA* strand, is degraded. Recently, some miRNA* sequences were reported to be abundantly expressed, and generally are less conserved across species. This situation is particularly evident for miR-9* with high levels of nucleotide divergence despite of their partners were highly conserved (Figure 8).

\section{Amphioxus miRNAs show spatially localized expression in CNS}

The CNS of larval amphioxus comprises an anterior cerebral vesicle (diencephalon plus small midbrain) and a long nerve cord (hindbrain plus spinal cord). The cerebral vesicle, includes the frontal eye rostrally, the infundibular organ ventrally and the lamellar organ dorsocaudally, which is also a photoreceptor. Just caudal to the infundibular organ, there is a thick ventral commissure (tegmental neuropile) receiving fibers that originate from the lamellate cells and just behind this is the primary motor centre (pmc) containing the anteriormost motoneurons and large premotor interneurons with caudal projections (Figure 9). The latter represents the ventral control locomotory system of amphioxus larva thought to be involved in initiating swimming and escape behaviors $[18,19,55]$. According to the microanatomical reconstructions and gene expression data, the posterior neural tube of amphioxus does not have segmented rhombomeres as vertebrates; but the collinear

\begin{tabular}{|c|c|c|c|c|c|c|}
\hline & 23 & & 1 & 23 & & 22 \\
\hline bbe-miR-9 & UCUUUGGUUAUCUAGCUGUAUG周 & bbe-miR-9* & 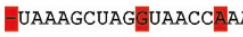 & $A A C$ & bbe-miR-184 & UGGACGGAGAACUGAUAAGE \\
\hline bfl-miR-9 & UCUUUGGUUAUCUAGCUGUAUG" & bfl-miR-9* & 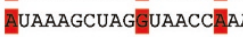 & & bfl-miR-184 & UGGACGGAGACUGAUAAGE \\
\hline bj-miR-9 & UCUUUGGUUAUCUAGCUGUAUGU & pma-miR-9a* & \#UAAAGCUAG & AAGUA & bj-miR-184 & UGGACGGAGĀACUGAUAAG- \\
\hline pma-miR-9a & UCUUUGGUUAUCUAGCUGUAUG"- & dre-miR-9* & -UAaAgCuag & AAGU- & pma-miR-184 & UGGACGGAG \\
\hline dre-miR-9 & 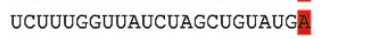 & hsa-miR-9* & 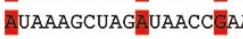 & AAGU- & dre-miR-184 & 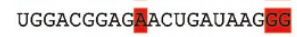 \\
\hline \multirow[t]{2}{*}{ hsa-miR-9 } & UCUUUGGUUAUCUAGCUGUAUGA & & & & hsa-miR-184 & UGGACGGAGA्ĀACUGAUAAGG \\
\hline & 22 & & & 1 & 23 & \\
\hline bbe-miR-7 & UGGAAGACUAGUGAUUUUGUUGU & & bbe-miR-124 & UAAGC & GGUGAAUGCCA & \\
\hline bfl-miR-7 & UGGAAGACUAGUGAUUUUGUUGU & & bfl-miR-124 & UAAGC & GGUGAAUGCCP & \\
\hline pma-miR-7a & UGGAAGACUAGUGAUUUUGUUGU & & bj-miR-124 & UAAGC & GGUGAAUGCC & \\
\hline dre-miR-7a & UGGAAGACUAGUGAUUUUGUUGU & & pma-miR-124 & UAAGC & GGUGAAUGCCA & \\
\hline \multirow[t]{3}{*}{ hsa-miR-7 } & UGGAAGACUAGUGAUUUUGUUGU & & dre-miR-124 & UAAGC & GGUGAAUGCCA & \\
\hline & & & hsa-miR-124 & UAAGC & GGUGAAUGCC- & \\
\hline & 24 & & & 1 & & 24 \\
\hline bbe-miR-137 & DuAuUgCuUG] & & bbe-miR-183 & UAUE & JGGUAGAAUUCACU & \\
\hline bfl-miR-137 & EUAUUGCUUGAGAAUACĀCGU & & bfl-miR-183 & UAUC & IGGUAGAAUUCACU & \\
\hline bj-miR-137 & 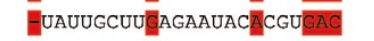 & & bj-miR-183 & UAUC & IGGUAGAAUUCAC- & \\
\hline pma-miR-137 & 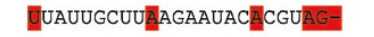 & & pma-miR-183 & UAUC & JGGUAGAAUUCACU & \\
\hline dre-miR-137 & 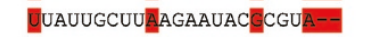 & & dre-miR-183 & UAUC & JGGUAGAAUUCACD & \\
\hline hsa-miR-137 & 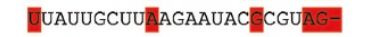 & & hsa-miR-183 & UAUC & JGGUAGAAUUCACE & \\
\hline \multicolumn{7}{|c|}{$\begin{array}{l}\text { Figure } 8 \text { Sequence alignment of mature miRNA sequences. The alignment was performed using the mature miRNA sequences of three } \\
\text { Branchiostoma species (belcherii, bbe; floridae, bfl; japonicum, bj) and three vertebrates (Homo sapiens, has; Danio rerio, dre; Petromyzon marinus, } \\
\text { pma). Different residues and insertions/deletions are highlighted in red in the alignment. The miR-9* sequence alignment showed several } \\
\text { differences between Branchiostoma sp. and vertebrates. The sequences of mature miRNAs of B. floridae, Homo sapiens, Danio rerio, Petromyzon } \\
\text { marinus were obtained from miRBase. The sequences of miRNAs of B. belcherii and B. japonicum from [12,13]. }\end{array}$} \\
\hline
\end{tabular}




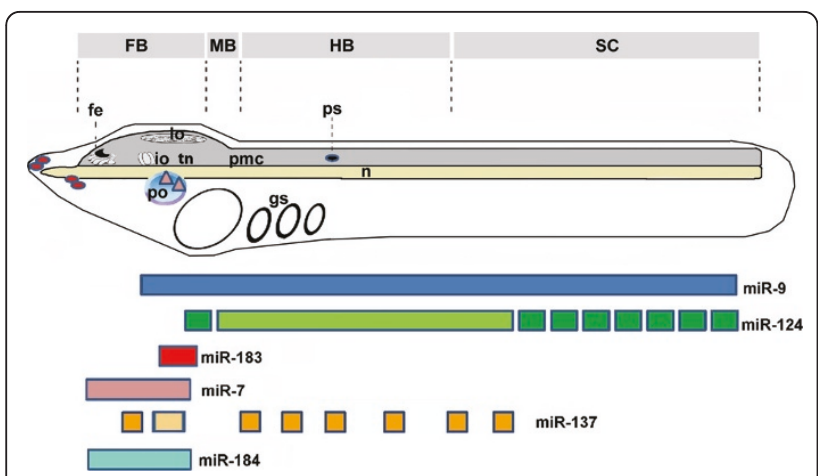

Figure 9 Schematic representation of the left side of amphioxus larva showing the expression of miRNAs in CNS and PNS. Above the figure the putative territories homologous to the vertebrate diencephalon (D), midbrain (M), hindbrain (HB) and spinal cord (SC) are reported. The expression of miRNAs are shown by colored boxes. Different color shades of boxes indicate different stages of development in which we observed the appearance of new expression domains (light green correspond to the expression of miR-124 up to larva with a first gill and dark green miR-124 expression at larva with 3-4 gill slits; light yellow indicates miR-137 expression until 48 hour larva and dark yellow miR-137 expression at 72 hour larva). miR-7 and miR-183 transcripts in the preoral organ and epidermal sensory cells of PNS (red spots and pink triangles respectively) are also represented. The position of the frontal eye complex (fe), infundibular cells (io), tegmental neuropile (tg), lamellar organ (lb) and primary motor centre (pmc) are indicated. The first pigment spot of dorsal ocellus is also indicate (ps) as well as preoral organ (po), gill slits (gs) and notochord (n).

expression pattern of AmphiHox, as well as the segmental expression pattern of islet in the amphioxus neural tube, suggests that amphioxus have at least a hindbrainrelated region [25,56] (Figure 9).

Our study shows that miRNAs in amphioxus are differentially expressed within the CNS suggesting that they have region-specific functions. Within the cerebral vesicle, miR-137 and miR-183 show restricted expression in specific cell types, whereas miR-184 and miR-7 are broadly expressed (Figure 9). In 48 h larvae, miR137 is expressed ventrally in the infundibular organ and likely more posterior in the tegmental neuropile, whereas miR-183 is found dorsal to the infundibulum. At the same stage, miR-124 is preferentially expressed in the hindbrain, whereas in the cerebral vesicle it appears to be limited to few cells in the more posterior part (Figure 9). Moreover, miR-124 expression is also probably found in both interneurons and motoneurons located ventro-laterally in the pmc. Regional expression of miR-9 is similar to that of miR-124, although the exact cells in the neural tube expressing the two may not be the same. The regionally restricted expression suggests that miRNAs may regulate specific cell types in the CNS of amphioxus. These miRNAs could act in the regionalization of the nervous system in a manner similar to that of miR-9 in the positioning of the midbrain-hindbrain boundary (MHB) in zebrafish [31]. In addition, expression of some amphioxus miRNAs suggested roles in neuronal specification and/or differentiation. For instance, miR-124 is initially expressed where five pairs of motor neurons develop in the hindbrain. This segmental pattern is very similar to that of several genes including islet, Krox, Mnx, ERR, Shox, synapsin and ChAT/VAChT [24-27,57,58]. However, neither of these genes seems to be recognized by miR- 124 .

\section{Conservation of miRNAs across species}

Given the sequence conservation of many miRNAs across species (Figure 8), it is perhaps not surprising that their developmental roles seem to be quite conserved as well. For example, miR-124 is a highly conserved miRNA expressed in the nervous systems not only of amphioxus and vertebrates, but also of several invertebrates including some lophotrochozoans and ecdysozoans, but not in C. elegans and Aplysia, where it is mostly confined to sensory neurons in the PNS [28,30,59-65]. In mammals, miR-124 is the most abundant miRNA in the embryonic and adult brain [60]. In particular, during neurogenesis, miR-124 is present at undetectable or very low levels in neural progenitors but is highly expressed in differentiating and mature neurons $[10,28,66,67]$. In amphioxus, miR-124 is expressed exclusively in the CNS, initially, in five groups of cells located ventro-laterally and ventrally in the midbrain and hindbrain at mid-neurula stage and later, more anteriorly, but still mostly in ventro-lateral neurons. Early expression of Neurogenin and ERR in the first motor neurons to differentiate is similar to that of miR$124[24,68]$. However, whether miR-124 is expressed in the same or adjacent cells is not certain. Certainly, more cells express miR-124 than expresses ERR.

In vertebrates, miR-124 is expressed in proliferating neuroblasts. However, in amphioxus, at least at the midneurula stage, expression of miR-124 seems to be in post-mitotic cells. At that stage, the only proliferating cells are in the most anterior and posterior-third of the neural tube [69] where miR-124 expression is not found. Interestingly, miR-124 expression was found in the most posterior part of the nerve cord only in later larvae, probably because of the delayed differentiation of neurons there.

miR-9 and miR-124 are both widely expressed in the amphioxus CNS, however cross-sections show that they are expressed in different cells with miR-124 being largely expressed ventrolaterally whereas miR-9 is expressed in the ventral midline. Moreover, unlike mir124 , miR-9 expression is limited to later larvae and it is likely not involved in neurogenesis as described in mammals. In addition the amphioxus miR-9* sequence in 
amphioxus has little sequence identity with its vertebrate counterparts (Figure 8), and like miR-9 it is probably not involved in the proliferation of neuronal progenitors.

Although amphioxus and vertebrate miR-9 genes are both expressed in the brain [60,70], unlike miR-124, the functions of miR-9 do not appear to be highly evolutionarily conserved across phyla. In zebrafish and mice, miR-9 is expressed in neural progenitor cells and promotes neurogenesis by repressing suppressors of neuronal differentiation. In addition, miR-9 also targets members of the transcriptional repressor REST complex, inhibiting the expression of neuronal genes in non-neuronal cells [29,71]. Several studies have suggested that miR-9 and miR-9* can both suppress progenitor proliferation and promote neural differentiation [66,71-73]. In zebrafish, miR-9 helps establish the MHB by antagonizing FGF signaling, thus, promoting neurogenesis [31]. However, miR-9 is also expressed in differentiated neurons of the telencephalon $[10,66,74]$. Moreover, miR-9 is one of four highest expressed miRNA genes in the adult brain of the lamprey Petromyzon marinus [75]. In contrast, in Drosophila embryos, miR-9 is not expressed in the CNS. Instead, it is expressed in ectodermal cells near some sensory organ precursors (SOPs), where it regulates the specification of sensory neurons by repressing the proneural gene senseless in the ectodermal non-SOP cells [76]. The difference between miR-9 function in Drosophila and vertebrates might be because miR-9 regulates different genes in these two organisms - for example, proneural genes in Drosophila and inhibitors of neurogenesis in vertebrates. In other protostomes, such as the annelid Platynereis dumerilii, miR-9 is expressed in cells at the base of the antennae, a pair of head appendages likely acting as chemosensory organs [59].

In amphioxus, miR-184 is ubiquitously expressed in early embryos and larvae although there is expression in the cerebral vesicle in later larvae (Figure 9). In other species, it is similarly widely expressed. For example, it is expressed not only in the CNS, but also in eye and testis of mouse, pharyngeal arch ectoderm and lateral plate mesoderm in the chick, and in the developing eye, hatching gland and epidermis in the zebrafish $[30,77]$. Similarly in the lamprey, miR-184 is expressed in several organs (brain, gills, kidney, heart, muscle) [75]. Moreover, in Drosophila, while miR-184 transcripts are present at high levels in the CNS, they are also present at high levels in eggs and during early embryogenesis in the mesoderm and anterior endoderm as well as in the female germline $[63,78,79]$.

Expression of miR-7 is comparatively evolutionarily conserved. In amphioxus, miR-7 expression in the CNS is limited to the cerebral vesicle (Figure 9). In late neurulae, it is expressed in the presumptive frontal eye, which consists of a cluster of pigment cells (the pigmented cup) and four rows of neurons [20] and where serotonin-containing cells will later differentiate [80]. In larvae, miR-7 transcripts also occur in the middle and posterior cerebral vesicle, including the infundibular cells. Interestingly, we also found miR-7 expression in developing preoral pit in amphioxus (Figure 9), which has been suggested to be homologous to the vertebrate pituitary [81-83].

In other species, miR-7 is also expressed in photoreceptors [84]. In Drosophila, together with repression of Yan protein (a repressor of retinal cell differentiation), miR-7 regulates photoreceptor differentiation induced by FGF signaling [85]. In the mouse, and zebrafish miR7 is also expressed in the hypothalamus in neurons with sensory or neurosecretory functions $[86,87]$. Similarly, in the annelid Platynereis, miR-7 is expressed in vasotocinergic, FMRFamidergic and serotonergic neurons. In addition, miR-7 is expressed in some non-neural tissues including endocrine cells of the pancreas (islets of Langerhans) [88] and in the pituitary gland in mammals [77]. In lamprey, miR-7 is expressed at the larval and adult stage. The brain is the major site of production of such miRNA, although other organs (kidney, skin and gills) express it at low levels [75].

Expression of miR-137 is also highly conserved across species. Vertebrate miR-137, like miR-7, is expressed in specific nuclei in the thalamus/hypothalamus and dorsal tegmentum [66] and enriched in the synaptic compartment of neurons in the mammalian forebrain $[89,90]$. In the annelid Platynereis, miR-137 and miR-7 are expressed in the same region of the CNS [59], while in amphioxus, miR-137 starts to be expressed in some cells of the infundibular organ and in the tegmental neuropile (Figure 9) [19,91]. Moreover, in later larvae it is also expressed in other regions of the cerebral vesicle and in the posterior neural tube. Outside the neural tube we also found expression in the mouth region and gill slits (Figures 7 and 8). Similarly, in the lamprey miR-137 is also expressed in the mouth as well as in the brain [75].

\section{miR-183 family members represent one of the most highly conserved regulators in sensory organ development}

In vertebrates, miR-183 family members (miR-182, miR96, and miR-183) are co-transcribed from a 1 to $4 \mathrm{~kb}$ segment of intergenic DNA [92] and miR-183 and miR96 genes appear to be adjacent in genomes of the urochordate Ciona intestinalis [93]. More recently, the genomic linkage of miR-182/miR-9/miR-183 has been described in other deuterostomes (Strongylocentrotus purpuratus, Saccoglossus kowalevskii and Branchiostoma 
floridae) [13]. Expression of miR-183 in sensory cells is highly conserved. In amphioxus, it is expressed in potential precursors of ectodermal sensory cells in the rostrum (Figure 9) [44] and, where the lamellar body, thought homologous to the epiphysis of agnathans [41], which also expresses miR-183 [30]. In vertebrates, the three miR 183 family members have very similar expression patterns in specific sensory cell types in the eye, nose, and inner ear $[30,40,92]$. miR-183 expression is also conserved in neuromasts of teleosts, amphibians and agnathans [93]. In mammals, the miR-183 family was predicted to recognize several genes known to have important roles in various sensory organs, supporting the hypothesis of the sensory organ specificity of this cluster [92]. In Drosophila and C. elegans, miR-183 homologs are also expressed in ciliated sensory cells of mechano- and chemo-sensory organs $[93,94]$. Similarly, in the hemichordate Saccoglossus kowalevskii, several potential neurosensory cells express miR-183 [93].

\section{Conclusion}

Many miRNAs are evolutionarily conserved and some have limited expression patterns with strict tissue, cell, and temporal specificities, while others demonstrate ubiquitous or constitutive expression. Moreover, the high phylogenetic conservation of several miRNAs suggests their ancient origin and crucial function in evolutionarily conserved developmental processes.

Our study has set the stage for future investigations of control of neuronal development by microRNA in amphioxus. Amphioxus is a particularly favorable model given the small number of neurons in this model chordate and previous studies mapping each neuron and its connections in the amphioxus brain. In light of the conservation of neural patterning and miRNA expression in amphioxus and vertebrates, results from amphioxus should be highly relevant to understanding the mechanisms of neuronal patterning in the more complex vertebrate brain.

\section{Methods}

Embryos collection and whole-mount in situ hybridisation Adults amphioxus (Branchiostoma floridae) were collected from Old Tampa Bay, FL, USA. In vitro fertilization, embryo culture, and fixation were performed as described [95]. Adults amphioxus (Branchiostoma lanceolatum) were collected in the bay of Argelès-sur-Mer, France, and gametes were obtained by heat stimulation $[96,97]$. Fixation was performed as described [95]. Expression patterns of mature miRNAs were determined by whole-mount in situ hybridizations using Locked Nucleic Acid (LNA)-modified oligonucleotide probes (WM-LNA-ISH). The sequences of mature miRNAs of B. floridae were obtained from miRBase release 17 [98]. LNA-modified probes were purchased from Exiqon
(Denmark) and were directly labeled with DIG at both their 5' and 3'-ends, or at 3'-ends only, as previously described [10]. The sequences of LNA probes are the following: miR-124: 5'-GGCATTCACCGCGTGCCTTA3'; miR-9: 5'-CATACAGCTAGATAACCAAAGA-3'; miR-7: 5'-ACAACAAAATCACTAGTCTTCCA-3'; miR183: 5'-AGTGAATTCTACCAGTGCCATA-3'; miR-184: 5'-CCCTTATCAGTTCTCCGTCCA-3'; miR-137: 5'ACGTGTATTCTCAAGCAAT-3'. Whole mount in situ hybridization was performed essentially as described by Holland and coworkers [95] with some modifications. In particular, the temperature of hybridization and subsequent washing steps was adjusted to approximately $22^{\circ} \mathrm{C}$ below the predicted melting temperatures of the LNA modified probes. All miRNA probes were used at the same concentration (final concentration $5 \mathrm{nM}$ ) and in parallel. To determine the miRNA expression patterns more precisely at the cellular level, some embryos were also sectioned. Labeled embryos were counterstained with $1 \%$ Ponceau $\mathrm{S}$ in $1 \%$ acetic acid, dehydrated in ethanol, embedded in Spurr's resin, and sectioned at 3 to $4 \mu \mathrm{m}$. Images were collected by using an Olympus IX71 microscope (Olympus Italia s.r.l., Italy) equipped with the chilled color digital camera ColorView II (Soft Imaging System GmbH, Germany) and images were processed using the analySIS software package (Soft Imaging System GmbH, Germany).

\section{Prediction of amphioxus microRNA target genes}

To identify potential target genes of the six miRNAs analyzed in the present paper we examined a suite of RNAs known to be expressed in the nervous system (Additional file 1 Table S2). Because the B. floridae genome is not fully annotated, and several transcripts did not contain the 5' UTR and 3' UTR regions we selected full-length cDNA sequences to allow identification of the stop codons and consequently the 3'UTRs. Therefore, sequences of 3'UTRs were obtained from the B. floridae EST data sets [99] and from the JGI web site [100]. To improve the accuracy of target prediction we used four target prediction algorithms: miRanda, RNAhybrid, FindTar, PITA [101-104]. miRNAs with binding sites in the 3'-UTR as predicted by three of the four bioinformatics algorithms were selected as putative regulators of transcripts (Table 1 and Additional file 1 Table S1). For target prediction with miRanda software we used the following parameters: gap opening penalty of -8 ; a gap extension penalty of -2 ; a score threshold of 60 ; an energy threshold of $-20 \mathrm{kcal} / \mathrm{mol}$; a scaling parameter of 2 . For RNAhybrid we considered only the sites with $\Delta \mathrm{G}$ $<-20 \mathrm{kcal} / \mathrm{mol}$, with seed 2 to 8 and allowing G:U wobble pairs. PITA identifies putative targets assigning an energetic score (ddG). Only sites with ddG values 
below -10 were considered as significant. For FindTar we used default parameters: loop score $>15$ and $\Delta \mathrm{G}<$ $-15 \mathrm{kcal} / \mathrm{mol}$. PITA, FindTar and miRanda executable can be downloaded from their specific websites [105-107]. RNAhybrid is available at BIBiserv [108].

\section{Additional material}

Additional file 1: Amphioxus putative miRNA targets. Additional file 1, Table S1: Amphioxus putative miRNA targets expressed in the nervous system. Score values, energetic scores $(d d G)$, free energy $(\Delta G)$ and loop scores produced by the different target prediction tools are shown. Additional file 1, Table S2: Complete list of transcripts analyzed by miRNA target prediction programs.

\section{Abbreviations}

miRNA: microRNA; UTRs: untranslated regions; CNS: central nervous system; B. floridae and B-lanceolatum: Branchiostoma floridae and Branchiostoma lanceolatum; PNS: peripheral nervous system; REST/NRSF: RE1 silencing transcription factor/neural-restrictive silencing factor; pmc: primary motor centre; MHB: midbrain-hindbrain boundary; SOPs: sensory organ precursors, WM-LNA-ISH: whole-mount in situ hybridizations using Locked nucleic acid (LNA)-modified oligonucleotide probes.

\section{Acknowledgements}

We would like to thank Skip Pierce and John M. Lawrence (Department of Biology, USF, Tampa, FL) for the use of laboratory space and equipment; Linda Holland (Scripps Institution of Oceanography, La Jolla, CA) for her comments and criticisms; Ray Martinez and Marilyn Wetzel (Department of Biology, USF, Tampa, FL) for their logistic support. We are deeply grateful to Héctor Escriva and collaborators (Centre National de la Recherche Scientifique, Unité Mixte de Recherche 7232, Université Pierre et Marie Curie Paris 06, ObservatoireOcéanologique, F-66651 Banyuls-sur-Mer, France) for the important support in collecting Branchiostoma lanceolatum adults and embryos and for providing us with laboratory space, scientific and technical assistance. This work was supported by MIUR (PRIN Program n 20088JEHW3001) (to SC and MP). DDPT was supported by intramural funds of Fondazione Istituto Italiano di Tecnologia.

\section{Author details}

'University of Genoa, Department of Biology, viale Benedetto XV 5, 16132 Genoa, Italy. ${ }^{2}$ The Italian Institute of Technology, Department of Neuroscience and Brain Technologies, Via Morego 30, 16163 Genova, Italy.

\section{Authors' contributions}

SC carried out the bioinformatic and in situ hybridization assays and drafted the manuscript. LM and GG contributed to the whole mount in situ experiments and bioinformatic analysis, respectively. DDPT was involved in the comparison of the miRNA and expression patterns and contributed to data discussion. SC and MP were responsible for the cellular and evolutionary interpretation of the data. All authors read and approved the final manuscript.

\section{Competing interests}

The authors declare that they have no competing interests.

Received: 7 April 2011 Accepted: 1 July 2011 Published: 1 July 2011

\section{References}

1. Bartel B, Bartel DP: MicroRNAs: at the root of plant development? Plant Physiol 2003, 132:709-717.

2. Lagos-Quintana M, Rauhut R, Lendeckel W, Tuschl T: Identification of novel genes coding for small expressed RNAs. Science 2001, 294:853-858.

3. Ambros $\mathrm{V}$ : The functions of animal microRNAs. Nature $2004,431: 350-355$
4. Grimson A, Srivastava M, Fahey B, Woodcroft BJ, Chiang HR, King N, Degnan BM, Rokhsar DS, Bartel DP: Early origins and evolution of microRNAs and Piwi-interacting RNAs in animals. Nature 2008, 455:1193-1197.

5. Bartel DP: MicroRNAs: genomics, biogenesis, mechanism, and function. Cell 2004, 116:281-297.

6. Pasquinelli AE, Hunter S, Bracht J: MicroRNAs: a developing story. Curr Opin Genet Dev 2005, 15:200-205.

7. Esquela-Kerscher A, Slack FJ: Oncomirs - microRNAs with a role in cancer. Nat Rev Cancer 2006, 6:259-269.

8. Sempere LF, Freemantle S, Pitha-Rowe I, Moss E, Dmitrovsky E, Ambros V: Expression profiling of mammalian microRNAs uncovers a subset of brain-expressed microRNAs with possible roles in murine and human neuronal differentiation. Genome Biol 2004, 5:R13.

9. Liu K, Liu Y, Mo W, Qiu R, Wang X, Wu JY, He R: miR-124 regulates early neurogenesis in the optic vesicle and forebrain, targeting NeuroD1. Nucleic Acids Res 2011, 1:1-11.

10. De Pietri Tonelli D, Calegari F, Fei JF, Nomura T, Osumi N, Heisenberg CP, Huttner WB: Single-cell detection of microRNAs in developing vertebrate embryos after acute administration of a dual-fluorescence reporter/ sensor plasmid. Biotechniques 2006, 41:727-732.

11. Dai Z, Chen Z, Ye H, Zhou L, Cao L, Wang Y, Peng S, Chen L: Characterization of microRNAs in cephalochordates reveals a correlation between microRNA repertoire homology and morphological similarity in chordate evolution. Evol Dev 2009, 11:41-49.

12. Chen X, Li Q, Wang J, Guo X, Jiang X, Ren Z, Weng C, Sun G, Wang X, Liu Y, Ma L, Chen JY, Wang J, Zen K, Zhang J, Zhang CY: Identification and characterization of novel amphioxus microRNAs by Solexa sequencing. Genome Biol 2009, 10:R78.

13. Campo-Paysaa F, Sémon M, Cameron RA, Peterson KJ, Schubert M: microRNA complements in deuterostomes: origin and evolution of microRNAs. Evol Dev 2011, 13:15-27.

14. Putnam NH: The amphioxus genome and the evolution of the chordate karyotype. Nature 2008, 453:1064-1071.

15. Holland $L Z$ : The amphioxus genome illuminates vertebrate origins and cephalochordate biology. Genome Res 2008, 18:1100-1111.

16. Nicol D, Meinertzhagen IA: Cell counts and maps in the larval central nervous system of the ascidian Ciona intestinalis (L.). J Comp Neurol 1991 309:415-429.

17. Yu JK, Meulemans D, McKeown SJ, Bronner-Fraser M: Insights from the amphioxus genome on the origin of vertebrate neural crest. Genome Res 2008, 18:1127-1132.

18. Holland LZ, Holland ND: Chordate origins of the vertebrate central nervous system. Curr Opin Neurobiol 1999, 9:596-602.

19. Wicht H, Lacalli TC: The nervous system of amphioxus: structure, development, and evolutionary significance. Can J Zool 2005, 83:122-150.

20. Lacalli TC: Frontal eye circuitry, rostral sensory pathways and brain organization in amphioxus larvae: evidence from 3D reconstructions. Philos Transact R Soc B: Biol Sci 1996, 351:243-263.

21. Williams NA, Holland P WH: Old head on young shoulders. Nature 1996, 383:490.

22. Holland LZ, Holland ND: Expression of AmphiHox-1 and AmphiPax-1 in amphioxus embryos treated with retinoic acid: insights into evolution and patterning of the chordate nerve cord and pharynx. Development 1996, 122:1829-1838.

23. Castro LF, Rasmussen SL, Holland PW, Holland ND, Holland LZ: A Gbx homeobox gene in amphioxus: insights into ancestry of the ANTP class and evolution of the midbrain/hindbrain boundary. Dev Biol 2006, 295:40-51.

24. Bardet PL, Schubert M, Horard B, Holland LZ, Laudet V, Holland ND, Vanacker JM: Expression of estrogen-receptor related receptors in amphioxus and zebrafish: implications for the evolution of posterior brain segmentation at the invertebrate-to-vertebrate transition. Evol Dev 2005, 7:223-333.

25. Jackman WR, Langeland JA, Kimmel CB: islet reveals segmentation in the amphioxus hindbrain homolog. Dev Biol 2000, 220:12-26.

26. Jackman WR, Kimmel CB: Coincident iterated gene expression in the amphioxus neural tube. Evol Dev 2002, 4:366-374.

27. Ferrier DE, Brooke NM, Panopoulou G, Holland PW: The Mnx homeobox gene class defined by HB9, MNR2 and amphioxus AmphiMnx. Dev Genes Evol 2001, 211:103-107. 
28. Deo M, Yu JY, Chung KH, Tippens M, Turner DL: Detection of mammalian microRNA expression by in situ hybridization with RNA oligonucleotides. Dev Dynamics 2006, 235:2538-2548.

29. Conaco C, Otto S, Han JJ, Mandel G: Reciprocal actions of REST and a microRNA promote neuronal identity. Proc Natl Acad Sci USA 2006 103:2422-2427.

30. Wienholds E, Kloosterman WP, Miska E, Alvarez-Saavedra E, Berezikov E, de Bruijn E, Horvitz HR, Kauppinen S, Plasterk RH: MicroRNA expression in zebrafish embryonic development. Science 2005, 309:310-311.

31. Leucht C, Stigloher C, Wizenmann A, Klafke R, Folchert A, Bally-Cuif L: MicroRNA-9 directs late organizer activity of the midbrain-hindbrain boundary. Nat Neurosci 2008, 11:641-648.

32. Kloosterman WP, Wienholds E, de Bruijn E, Kauppinen S, Plasterk RH: In situ detection of miRNAs in animal embryos using LNA-modified oligonucleotide probes. Nat Methods 2006, 3:27-29.

33. Kefas B, Godlewski J, Comeau L, Li Y, Abounader R, Hawkinson M, Lee J, Fine $\mathrm{H}$, Chiocca EA, Lawler S, Purow B: microRNA-7 inhibits the epidermal growth factor receptor and the Akt pathway and is down-regulated in glioblastoma. Cancer Res 2008, 68:3566-3572.

34. Ferretti E, De Smaele E, Po A, Di Marcotullio L, Tosi E, Espinola MS, Di Rocco C, Riccardi R, Giangaspero F, Farcomeni A, Nofroni I, Laneve P, Gioia U, Caffarelli E, Bozzoni I, Screpanti I, Gulino A: MicroRNA profiling in human medulloblastoma. Int I Cancer 2009, 124:568-577.

35. Wong TS, Liu XB, Wong BY, Ng RW, Yuen AP, Wei WI: Mature miR-184 as Potential Oncogenic microRNA of Squamous Cell Carcinoma of Tongue. Clin Cancer Res 2008, 14:2588-2592.

36. Chen Y, Stallings RL: Differential patterns of microRNA expression in neuroblastoma are correlated with prognosis, differentiation, and apoptosis. Cancer Res 2007, 67:976-983.

37. Szulwach KE, Li X, Smrt RD, Li Y, Luo Y, Lin L, Santistevan NJ, Li W, Zhao X, Jin P: Cross talk between microRNA and epigenetic regulation in adult neurogenesis. J Cell Biol 2010, 189:127-141.

38. Smrt RD, Szulwach KE, Pfeiffer RL, Li X, Guo W, Pathania M, Teng ZQ, Luo Y, Peng J, Bordey A, Jin P, Zhao X: MicroRNA miR-137 regulates neuronal maturation by targeting ubiquitin ligase mind bomb-1. Stem Cells 2010, 28:1060-1070.

39. Friedman LM, Dror AA, Mor E, Tenne T, Toren G, Satoh T, Biesemeier DJ, Shomron N, Fekete DM, Hornstein E, Avraham KB: MicroRNAs are essential for development and function of inner ear hair cells in vertebrates. Proc Natl Acad Sci USA 2009, 106:7915-7920.

40. Sacheli R, Nguyen L, Borgs $L$, Vandenbosch R, Bodson M, Lefebvre P, Malgrange B: Expression patterns of miR-96, miR-182 and miR-183 in the development inner ear. Gene Expr Patterns 2009, 9:364-370.

41. Lacalli TC, Holland ND, West JE: Landmarks in the anterior central nervous system of amphioxus larvae. Philos Transact R Soc B 1994, 344:165-185.

42. Lacalli TC, Kelly SJ: The infundibular balance organ in amphioxus larvae and related aspects of cerebral vesicle organization. Acta Zool (Stockholm) 2000, 81:37-47.

43. Lacalli TC: Ventral neurons in the anterior nerve cord of amphioxus larvae. II. Further data on the pacemaker circuit. J Morphol 2003, 257:212-218.

44. Baatrup E: On the Structure of the Corpuscles of de Quatrefages (Branchiostoma lanceolatum (P)). Acta Zool (Stockholm) 1982, 63:39-44.

45. Ronshaugen M, Biemar F, Piel J, Levine M, Lai EC: The Drosophila microRNA iab-4 causes a dominant homeotic transformation of halteres to wings. Genes Dev 2005, 19:2947-2952.

46. Stark A, Brennecke J, Bushati N, Russell RB, Cohen SM: Animal microRNAs confer robustness to gene expression and have a significant impact on 3'UTR evolution. Cell 2005, 123:1133-1146.

47. Stark A, Bushati N, Jan CH, Kheradpour P, Hodges E, Brennecke J, Bartel DP, Cohen SM, Kellis M: A single Hox locus in Drosophila produces functional microRNAs from opposite DNA strands. Genes Dev 2008, 22:8-13.

48. Tsang J, Zhu J, van Oudenaarden A: MicroRNA-mediated feedback and feedforward loops are recurrent network motifs in mammals. $\mathrm{Mol}$ Cell 2007, 26:753-767.

49. Farh KK, Grimson A, Jan C, Lewis BP, Johnston WK, Lim LP, Burge CB, Bartel DP: The widespread impact of mammalian microRNAs on mRNA repression and evolution. Science 2005, 310:1817-1821.
50. Sood P, Krek A, Zavolan M, Macino G, Rajewsky N: Cell-type-specific signatures of microRNAs on target mRNA expression. Proc Natl Acad Sci USA 2006, 103:2746-2751.

51. Kuhn DE, Martin MM, Feldman DS, Terry AV Jr, Nuovo GJ, Elton TS: Experimental validation of miRNA targets. Methods 2008, 44:47-54

52. Somorjai I, Bertrand S, Camasses A, Haguenauer A, Escriva H: Evidence for stasis and not genetic piracy in developmental expression patterns of Branchiostoma lanceolatum and Branchiostoma floridae, two amphioxus species that have evolved independently over the course of $200 \mathrm{Myr}$. DevGenes Evol 2008, 218:703-713.

53. Cañestro C, Albalat R, Hjelmqvist L, Godoy L, Jörnvall H, Gonzàlez-Duarte R: Ascidian and amphioxus Adh genes correlate functional and molecular features of the ADH family expansion during vertebrate evolution. $J \mathrm{Mol}$ Evol 2002, 54:81-89.

54. Nohara M, Nishida M, Manthacitra V, Nishikawa T: Ancient phylogenetic separation between Pacific and Atlantic cephalochordates as revealed by mitochondrial genome analysis. Zool Sci 2004, 21:203-210.

55. Shimeld SM, Holland ND: Amphioxus molecular biology: insights into vertebrate evolution and developmental mechanisms. Can J Zool 2005, 83:90-100.

56. Wada H, Holland PW: Colinear and segmental expression of amphioxus Hox genes. DevBiol 1999, 213:131-141.

57. Candiani S, Lacalli TC, Parodi M, Oliveri D, Pestarino M: The cholinergic gene locus in amphioxus: molecular characterization and developmental expression patterns. Dev Dynamics 2008, 237:1399-1411.

58. Candiani S, Moronti L, Pennati R, De Bernardi F, Benfenati F, Pestarino M: The synapsin gene family in basal chordates: evolutionary perspectives in metazoans. BMC EvolBiol 2010, 10:32.

59. Christodoulou F, Raible F, Tomer R, Simakov O, Trachana K, Klaus S, Snyman H, Hannon GJ, Bork P, Arendt D: Ancient animal microRNAs and the evolution of tissue identity. Nature 2010, 463:1084-1088.

60. Lagos-Quintana M, Rauhut R, Yalcin A, Meyer J, Lendeckel W, Tuschl T: Identification of tissue-specific microRNAs from mouse. Current Biol 2002, 12:735-739.

61. Aboobaker AA, Tomancak P, Patel N, Rubin GM, Lai EC: Drosophila microRNAs exhibit diverse spatial expression patterns during embryonic development. Proc Natl Acad Sci USA 2005, 102:18017-18022.

62. Darnell DK, Kaur S, Stanislaw S, Konieczka JH, Yatskievych TA, Antin PB: MicroRNA expression during chick embryo development. DevDynamics 2006, 235:3156-3165

63. Watanabe T, Takeda A, Mise K, Okuno T, Suzuki T, Minami N, Imai H: Stagespecific expression of microRNAs during Xenopus development. FEBS Letters 2005, 579:318-324.

64. Clark AM, Goldstein LD, Tevlin M, Tavare S, Shaham S, Miska EA: The microRNA miR-124 controls gene expression in the sensory nervous system of Caenorhabditis elegans. Nucleic Acids Res 2010, 38:3780-3793.

65. Rajasethupathy P, Fiumara F, Sheridan R, Betel D, Puthanveettil SV, Russo JJ, Sander C, Tuschl T, Kandel E: Characterization of small RNAs in Aplysia reveals a role for miR-124 in constraining synaptic plasticity through CREB. Neuron 2009, 63:803-817.

66. De Pietri Tonelli D, Pulvers JN, Haffner C, Murchison EP, Hannon GJ, Huttner WB: miRNAs are essential for survival and differentiation of newborn neurons but not for expansion of neural progenitors during early neurogenesis in the mouse embryonic neocortex. Development 2008, 135:3911-3921.

67. Makeyev EV, Zhang J, Carrasco MA, Maniatis T: The MicroRNA miR-124 promotes neuronal differentiation by triggering brain-specific alternative pre-mRNA splicing. Mol Cell 2007, 27:435-448.

68. Holland LZ, Schubert M, Holland ND, Neuman T: Evolutionary conservation of the presumptive neural plate markers AmphiSox1/2/3 and AmphiNeurogenin in the invertebrate chordate amphioxus. Dev Biol 2000, 226:18-33.

69. Holland ND, Holland LZ: Stage- and tissue-specific patterns of cell division in embryonic and larval tissues of amphioxus during normal development. Evol Dev 2006, 8:142-149.

70. Giraldez AJ, Cinalli RM, Glasner ME, Enright AJ, Thomson JM, Baskerville S, Hammond SM, Bartel DP, Schier AF: MicroRNAs regulate brain morphogenesis in zebrafish. Science 2005, 308:833-838.

71. Packer AN, Xing Y, Harper SQ, Jones L, Davidson BL: The bifunctional microRNA miR-9/miR-9* regulates REST and CoREST and is downregulated in Huntington's disease. J Neurosci 2008, 28:14341-14346. 
72. Yoo AS, Staahl BT, Chen L, Crabtree GR: MicroRNA-mediated switching of chromatin-remodelling complexes in neural development. Nature 2009, 460:642-646.

73. Zhao C, Sun G, Li S, Shi Y: A feedback regulatory loop involving microRNA-9and nuclear receptor TLX in neural stem cell fate determination. Nat Struct Mol Biol 2009, 16:365-371.

74. Kapsimali M, Kloosterman WP, de Bruijn E, Rosa F, Plasterk RH, Wilson SW: MicroRNAs show a wide diversity of expression profiles in the developing and mature central nervous system. Genome Biol 2007, 8: R173.

75. Heimberg AM, Cowper-Sal-lari R, Sémon M, Donoghue PC, Peterson KJ: MicroRNAs reveal the interrelationships of hagfish, lampreys, and gnathostomes and thenature of the ancestral vertebrate. ProcNatl Acad Sci USA 2010, 107:19379-19383.

76. Li Y, Wang F, Lee JA, Gao FB: MicroRNA-9a ensures the precise specification of sensory organ precursors in Drosophila. Genes Dev 2006, 20:2793-2805.

77. Bak M, Silahtaroglu A, Møller M, Christensen M, Rath MF, Skryabin B, Tommerup N, Kauppinen S: MicroRNA expression in the adult mouse central nervous system. RNA 2008, 14:432-444.

78. lovino N, Pane A, Gaul U: miR-184 has multiple roles in Drosophila female germline development. Dev Cell 2009, 17:123-133.

79. Li P, Peng J, Hu J, Xu Z, Xie W, Yuan L: Localized expression pattern of miR-184 in Drosophila. Mol Biol Rep 2011, 38:355-358.

80. Holland ND, Holland LZ: Serotonin-containing cells in the nervous system and other tissues during ontogeny of a lancelet, Branchiostoma floridae. Acta Zool 1993, 74:195-204.

81. Candiani S, Pestarino M: Expression of the tissue-specific transcription factor Pit-1 in the lancelet, Branchiostoma lanceolatum. J Comp Neurol 1998, 392:343-351.

82. Glardon S, Holland LZ, Gehring WJ, Holland ND: Isolation and developmental expression of the amphioxus Pax-6 gene (AmphiPax-6): insights into eye and photoreceptor evolution. Development 1998, 125:2701-2710.

83. Candiani S, Holland ND, Oliveri D, Parodi M, Pestarino M: Expression of the amphioxus Pit-1 gene (AmphiPOU1F1/Pit-1) exclusively in the developing preoral organ, a putative homolog of the vertebrate adenohypophysis. Brain Res Bull 2008, 75:324-330.

84. Arora A, McKay GJ, Simpson DA: Prediction and verification of miRNA expression in human and rat retinas. Invest Ophthalmol Vis Sci 2007, 48:3962-3967.

85. Li X, Carthew RW: A microRNA mediates EGF receptor signaling and promotes photoreceptor differentiation in the Drosophila eye. Cell 2005, 123:1267-1277.

86. Lee HJ, Palkovits M, Young WS: miR-7b, a microRNA up-regulated in the hypothalamus after chronic hyperosmolar stimulation, inhibits Fos translation. Proc Natl Acad Sci USA 2006, 103:15669-15674.

87. Tessmar-Raible K, Raible F, Christodoulou F, Guy K, Rembold M, Hausen H, Arendt D: Conserved sensory-neurosecretory cell types in annelid and fish forebrain: insights into hypothalamus evolution. Cell 2007, 129:1389-1400.

88. Bravo-Egana V, Rosero S, Molano RD, Pileggi A, Ricordi C, DomínguezBendala J, Pastori RL: Quantitative differential expression analysis reveals miR-7 as major islet microRNA. Biochem Biophys Res Commun 2008, 366:922-926.

89. Siegel G, Obernosterer G, Fiore R, Oehmen M, Bicker S, Christensen M, Khudayberdiev S, Leuschner PF, Busch CJ, Kane C, Hübel K, Dekker F, Hedberg C, Rengarajan B, Drepper C, Waldmann H, Kauppinen S, Greenberg ME, Draguhn A, Rehmsmeier M, Martinez J, Schratt GM: A functional screen implicates microRNA-138-dependent regulation of the depalmitoylation enzyme APT1 in dendritic spine morphogenesis. Nat Cell Biol 2009, 11:705-716.

90. Silber J, Lim DA, Petritsch C, Persson Al, Maunakea AK, Yu M, Vandenberg SR, Ginzinger DG, James CD, Costello JF, Bergers G, Weiss WA Alvarez-Buylla A, Hodgson JG: miR-124 and miR-137 inhibit proliferation of glioblastoma multiforme cells and induce differentiation of brain tumor stem cells. BMC Med 2008, 6:14.

91. Olsson R, Yulis R, Rodriguez EM: The infundibular organ of the lancelet: an immunocytochemical study. Cell Tissue Res 1994, 277:107-114.
92. Xu S, Witmer PD, Lumayag S, Kovacs B, Valle D: MicroRNA (miRNA) transcriptome of mouse retina and identification of a sensory organspecific miRNA cluster. J Biol Chem 2007, 282:25053-25066.

93. Pierce ML, Weston MD, Fritzsch B, Gabel HW, Ruvkun G, Soukup GA: MicroRNA-183 family conservation and ciliated neurosensory organ expression. Evol Dev 2008, 10:106-113

94. Hilgers V, Bushati N, Cohen SM: Drosophila microRNAs 263a/b confer robustness during development by protecting nascent sense organs from apoptosis. PLOS Biol 2010, 8:e1000396.

95. Holland LZ, Holland PWH, Holland ND, Ferraris JD, Palumbi SR: Revealing homologies between body parts of distantly related animals by in situ hybridization to developmental genes: amphioxus versus vertebrates. In Molecular Zoology: Advances, Strategies, and Protocols. Volume 267. Edited by: Ferraris JD, Palumbi SR. New York: Wiley Press; 1996-282, 473-483.

96. Fuentes M, Schubert M, Dalfo D, Candiani S, Benito E, Gardenyes J, Godoy L, Moret F, Illas M, Patten I, Permanyer J, Oliveri D, Boeuf G, Falcon J, Pestarino M, Fernandez JG, Albalat R, Laudet V, Vernier P, Escriva H: Preliminary observations on the spawning conditions of the European amphioxus (Branchiostoma lanceolatum) in captivity. J Exp Zool B: Mol Dev Evol 2004, 302:384-391.

97. Fuentes M, Benito E, Bertrand S, Paris M, Mignardot A, Godoy L, JimenezDelgado S, Oliveri D, Candiani S, Hirsinger E, D'Aniello S, Pascual-Anaya J, Maeso I, Pestarino M, Vernier P, Nicolas JF, Schubert M, Laudet V, Geneviere AM, Albalat R, Garcia Fernandez J, Holland ND, Escriva H: Insights into spawning behavior and development of the European amphioxus (Branchiostoma lanceolatum). J Exp Zool Part B: Mol Dev Evol 2007, 308:484-493.

98. miRBAse:[http://www.mirbase.org/].

99. cDNA Database of Branchiostoma floridae:[http://amphioxus.icob.sinica.edu tw/].

100. JGl web site:[http://genome.jgi-psf.org/Brafl1/Brafl1.home.html].

101. Enright AJ, John B, Gaul U, Tuschl T, Sander C, Marks DS: MicroRNA targets in Drosophila. Genome Biol 2003, 5(1):R1.

102. Rehmsmeier M, Steffen $P$, Hochsmann M, Giegerich R: Fast and effective prediction of microRNA/target duplexes. RNA 2004, 10:1507-1517.

103. Ye W, Lv Q, Wong CK, Hu S, Fu C, Hua Z, Cai G, Li G, Yang BB, Zhang Y: The effect of central loops in miRNA:MRE duplexes on the efficiency of miRNA-mediated gene regulation. PLoS One 2008, 3:e1719.

104. Kertesz M, lovino N, Unnerstall U, Gaul U, Segal E: The role of site accessibility in microRNA target recognition. Nat Genet 2007, 39:1278-1284.

105. PITA:[http://genie.weizmann.ac.il/pubs/mir07/mir07_exe.html].

106. FindTar3:[http://bio.sz.tsinghua.edu.cn/content/download].

107. miRanda:[http://cbio.mskcc.org/research/sander/data/miRNA2003/ miranda new.html].

108. RNAhybrid:[http://bibiserv.techfak.uni-bielefeld.de/rnahybrid/submission. html].

109. Li B, Lin Y, Zhang W, Shao M, Bian Y, Huang S, Feng L, Zhang H: Developmental expression pattern of calmodulin gene in amphioxus Branchiostoma belcheri tsingtauense. Chinese J Oceanol 2010, 28:1221-1226.

110. Yu JK, Satou Y, Holland ND, Shin-I T, Kohara Y, Satoh N, Bronner-Fraser M, Holland LZ: Axial patterning in cephalochordates and the evolution of the organizer. Nature 2007, 445:613-617.

111. Mazet F, Masood S, Luke GN, Holland ND, Shimeld SM: Expression of AmphiCoe, an amphioxus COE/EBF gene, in the developing central nervous system and epidermal sensory neurons. Genesis 2004, 38:58-65.

112. Holland LZ, Kene M, Williams NA, Holland ND: Sequence and embryonic expression of the amphioxus engrailed gene (AmphiEn): the metameric pattern of transcription resembles that of its segment-polarity homolog in Drosophila. Development 1997, 124:1723-1732.

113. Torreson H, Martinez-Barbera JP, Beardsley A, Cubit X, Krauss S: Conservation of BF-1 expression in amphioxus and zebrafish suggests evolutionary ancestry of anterior cell types that contribute to the vertebrate telencephalon. Dev Genes Evol 1998, 208:431-439.

114. Minguillón C, Jiménez-Delgado S, Panopoulou G, Garcia-Fernàndez J: The amphioxus Hairy family: differential fate after duplication. Development 2003, 130:5903-5914.

115. Shimeld S: An amphioxus netrin gene is expressed in midline structures during embryonic and larval development. Dev Genes Evol 2000, 210:337-344. 
116. Holland LZ, Venkatesh TV, Gorlin A, Bodmer R, Holland ND:

Characterization and developmental expression of AmphiNk2-2, an NK2 class homeobox gene from Amphioxus. (Phylum Chordata; Subphylum Cephalochordata). Dev Genes Evol 1998, 208:100-105.

117. Kozmik Z, Holland ND, Kalousova A, Paces J, Schubert M, Holland LZ: Characterization of an amphioxus paired box gene, AmphiPax2/5/8: developmental expression patterns in optic support cells, nephridium, thyroid-like structures and pharyngeal gill slits, but not in the midbrainhindbrain boundary region. Development 1999, 126:1295-1304.

118. Kozmik Z, Holland ND, Kreslova J, Oliveri D, Schubert M, Jonasova K, Holland LZ, Pestarino M, Benes V, Candiani S: Pax-Six-Eya-Dach network during amphioxus development: conservation in vitro but context specificity in vivo. Dev Biol 2007, 306:143-159.

119. Langeland JA, Tomsa JM, Jackman WR Jr, Kimmel CB: An amphioxus snail gene: expression in paraxial mesoderm and neural plate suggests a conserved role in patterning the chordate embryo. Dev Genes Evol 1998, 208:569-577.

120. Candiani S, Oliveri D, Parodi M, Castagnola P, Pestarino M: AmphiD1/beta, a dopamine D1/beta-adrenergic receptor from the amphioxus Branchiostoma floridae: evolutionary aspects of the catecholaminergic system during development. Dev Genes Evol 2005, 215:631-638.

121. Escriva H, Holland ND, Gronemeyer H, Laudet V, Holland LZ: The retinoic acid signaling pathway regulates anterior/posterior patterning in the nerve cord and pharynx of amphioxus, a chordate lacking neural crest. Development 2002, 129:2905-2916.

122. Schubert M, Holland LZ, Panopoulou GD, Lehrach H, Holland ND: Characterization of amphioxus AmphiWnt8: insights into the evolution of patterning of the embryonic dorsoventral axis. Evol Dev 2000, 2:85-92.

doi:10.1186/2041-9139-2-15

Cite this article as: Candiani et al:: A study of neural-related microRNAs in the developing amphioxus. EvoDevo 2011 2:15.

\section{Submit your next manuscript to BioMed Central and take full advantage of:}

- Convenient online submission

- Thorough peer review

- No space constraints or color figure charges

- Immediate publication on acceptance

- Inclusion in PubMed, CAS, Scopus and Google Scholar

- Research which is freely available for redistribution

Submit your manuscript at www.biomedcentral.com/submit 